NEAR FIELD MODELING OF SPE1

EXPERIMENT AND PREDICTION OF

THE SECOND SOURCE PHYSICS

EXPERIMENTS (SPE2)

T. Antoun, H. Xu, O. Vorobiev, I. Lomov

October 25, 2011 
This document was prepared as an account of work sponsored by an agency of the United States government. Neither the United States government nor Lawrence Livermore National Security, LLC, nor any of their employees makes any warranty, expressed or implied, or assumes any legal liability or responsibility for the accuracy, completeness, or usefulness of any information, apparatus, product, or process disclosed, or represents that its use would not infringe privately owned rights. Reference herein to any specific commercial product, process, or service by trade name, trademark, manufacturer, or otherwise does not necessarily constitute or imply its endorsement, recommendation, or favoring by the United States government or Lawrence Livermore National Security, LLC. The views and opinions of authors expressed herein do not necessarily state or reflect those of the United States government or Lawrence Livermore National Security, LLC, and shall not be used for advertising or product endorsement purposes.

This work performed under the auspices of the U.S. Department of Energy by Lawrence Livermore National Laboratory under Contract DE-AC52-07NA27344. 


\section{NeAR FieLd Modeling of SPE1 experiment AND PREDICTION OF THE SECOND SOURCE Physics EXPERIMENTS (SPE2)}

Oleg Vorobiev, Heming Xu, Lew Glenn, Tarabay Antoun and Ilya Lomov Lawrence Livermore National Laboratory

Oct.24, 2011

LLNL-TR-528-449

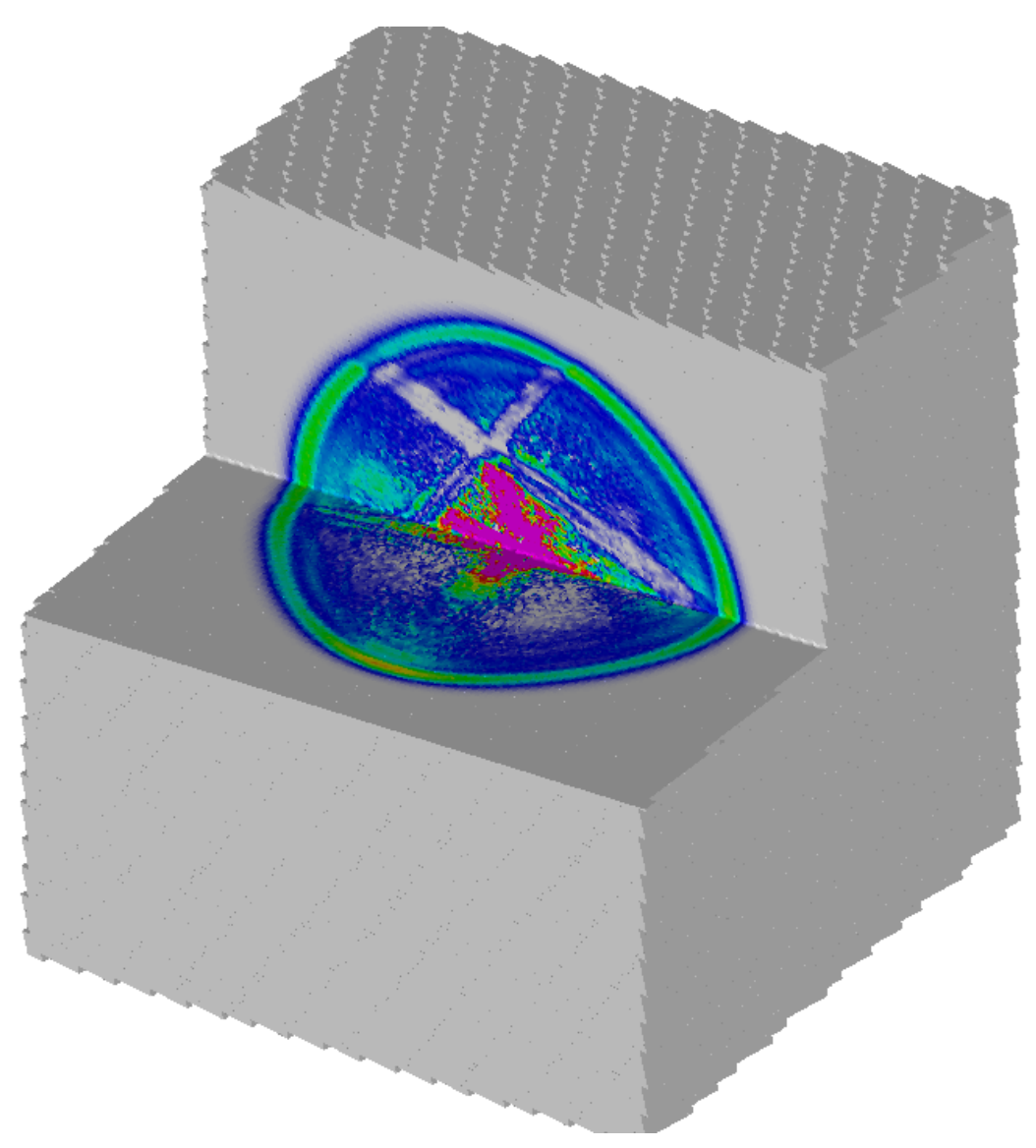




\section{Introduction}

Motion along joints and fractures in the rock has been proposed as one of the sources of near-source shear wave generation, and demonstrating the validity of this hypothesis is a focal scientific objective of the source physics experimental campaign in the Climax Stock granitic outcrop. A modeling effort has been undertaken by LLNL to complement the experimental campaign, and over the long term provide a validated computation capability for the nuclear explosion monitoring community. Our approach involves performing the near-field nonlinear modeling with hydrodynamic codes (e.g., GEODYN, GEODYN-L), and the far-field seismic propagation with an elastic wave propagation code (e.g., WPP). The codes will be coupled together to provide a comprehensive source-to-sensor modeling capability. Our technical approach involves pre-test predictions of each of the SPE experiments using our state of the art modeling capabilities, followed by code improvements to alleviate deficiencies identified in the pre-test predictions. This spiral development cycle wherein simulations are used to guide experimental design and the data from the experiment used to improve the models is the most effective approach to enable a transition from the descriptive phenomenological models in current use to the predictive, hybrid physics models needed for a science-based modeling capability for nuclear explosion monitoring.

The objective of this report is to describe initial results of non-linear motion predictions of the first two SPE shots in the Climax Stock: a 220-lb shot at a depth of $180 \mathrm{ft}$ (SPE \#1), and a 2570-lb shot at a depth of $150 \mathrm{ft}$ (SPE \#2). The simulations were performed using the LLNL 'ensemble' granite model, a model developed to match velocity and displacement attenuation from HARDHAT, PILE DRIVER, and SHOAL, as well as Russian and French nuclear test data in granitic rocks [Antoun et al. (2001)]. This model represents the state of the art modeling capabilities as they existed when the SPE campaign was launched in 2010, and the simulation results presented here will establish a baseline that will be used for gauging progress as planned modeling improvements are implemented during the remainder of the SPE program.

Our initial simulations were performed under 2D axisymmetric conditions assuming the geologic medium to be a homogeneous half space. However, logging data obtained from the emplacement hole reveal two major faults that intersect the borehole at two different depth intervals (NSTec report, 2011) and four major joint sets. To evaluate the effect of these discrete structures on the wave forms generated we have performed $2 \mathrm{D}$ and $3 \mathrm{D}$ analysis with a Lagrangian hydrocode, GEODYN-L that shares the same material models with GEODYN but can 
explicitly take joints and fault into consideration. We discuss results obtained using these two different approaches in this report.

\section{COMPUTATIONAL TOOLS}

GEODYN: Most of the continuum simulations described here were performed using GEODYN-a massively parallel three-dimensional Eulerian code with adaptive mesh refinement capabilities [Lomov and Liu (2005)]. The constitutive model used in the simulations is the LLNL 'Ensemble' granite model. This model is nonlinear, thermodynamically consistent, and properly invariant under superposed rigid body motions [Rubin et al. (2000)]. The model assumes the material is isotropic and applies the mathematical structure of plasticity theory to capture the basic features of the mechanical response of geological materials, including the effects of bulking, yielding, material damage, and porous compaction on the material response. This model has been shown to be in good agreement with the static data of Schock et al. (1973), as well as explosion data in granite [Antoun et al. (2001)]. One of the shortcomings of this model is that it does not account for directional effects associated with wave propagation. Alleviating this shortcoming is one of the main objectives of the near-field modeling effort.

GEODYN-L: Discrete simulations were performed using a Lagrangian massively parallel three-dimensional code, GEODYN-L [Vorobiev, 2011]. This code was designed to model wave propagation through heavily jointed rock masses. Joints are treated using an advanced contact algorithm with history variables. In the simulations, the geological medium was represented as an assembly of intact rock blocks separated by joints. Two material models were used in GEODYN-L. The first, the LLNL 'Ensemble' granite model, was used to verify that both codes give the same results for the SPE1 problem modeled as a spherical explosion. The second, an intact model [Vorobiev, 2008] was built to match available lab data for the granite samples from the site. Figure 1 shows an unconfined compressive strength test simulated with that model. The intact granite model was used to model response within each block of the rock mass. The net response depended on both intact material and joint models. 


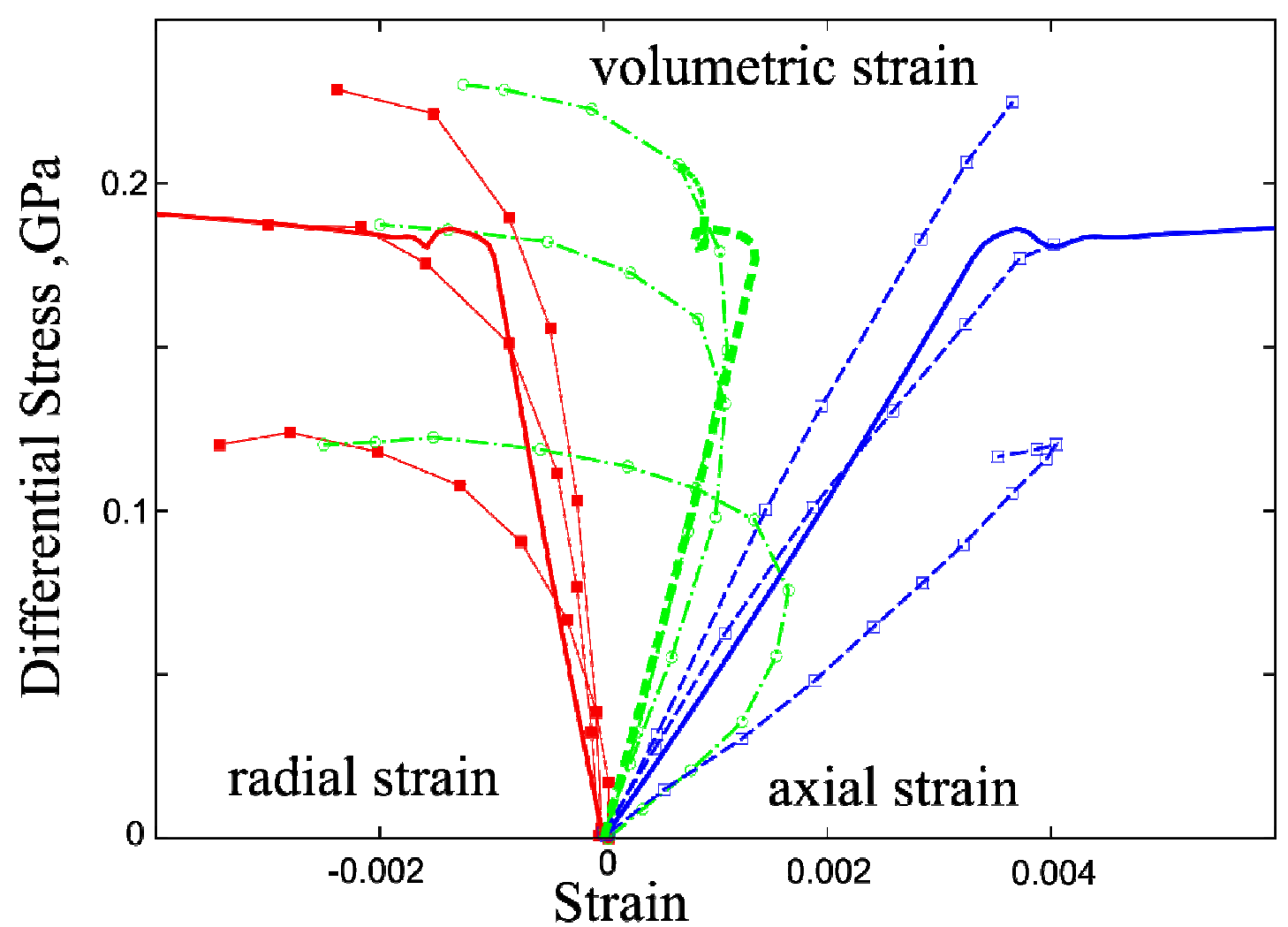

Figure 1 Comparison of model fits to unconfined compressive strength test for intact granite samples from the SPE test bed. Bold lines are simulation results, and thinner lines with markers a re experimental data

\section{D PARAMETRIC STUDY WITH GEODYN-L}

Parametric studies were performed in 2D to investigate the role of joints on the wave forms produced by a cylindrical explosion in intact granite. The intact granite is stronger than the in situ granite described by the 'ensemble' model, therefore fault effects would be expected to be more pronounced with GEODYN-L than in large-scale GEODYN simulations (with and without the faults). Figure 2 shows the location of the target points and the fault relative to the source.

In the limit when all joints are stiff and have high friction such a blocky system provides mechanical response very close to that of a continuum rock mass without joints. Figure 3 and Figure $\mathbf{4}$ show radial velocity profiles calculated at locations $A$ and $B$ both with and without the fault using either the continuum model (without joints, solid lines) or the discrete model with stiff joints (dashed lines). The same figures show that the presence of a sliding joint has a much 
more pronounced effect on the wave forms, dramatically increasing both the peak velocity and the width of the wave. The fault tends to widen the pulse in the direction parallel to the fault and have a very small effect in the normal-to-fault direction.

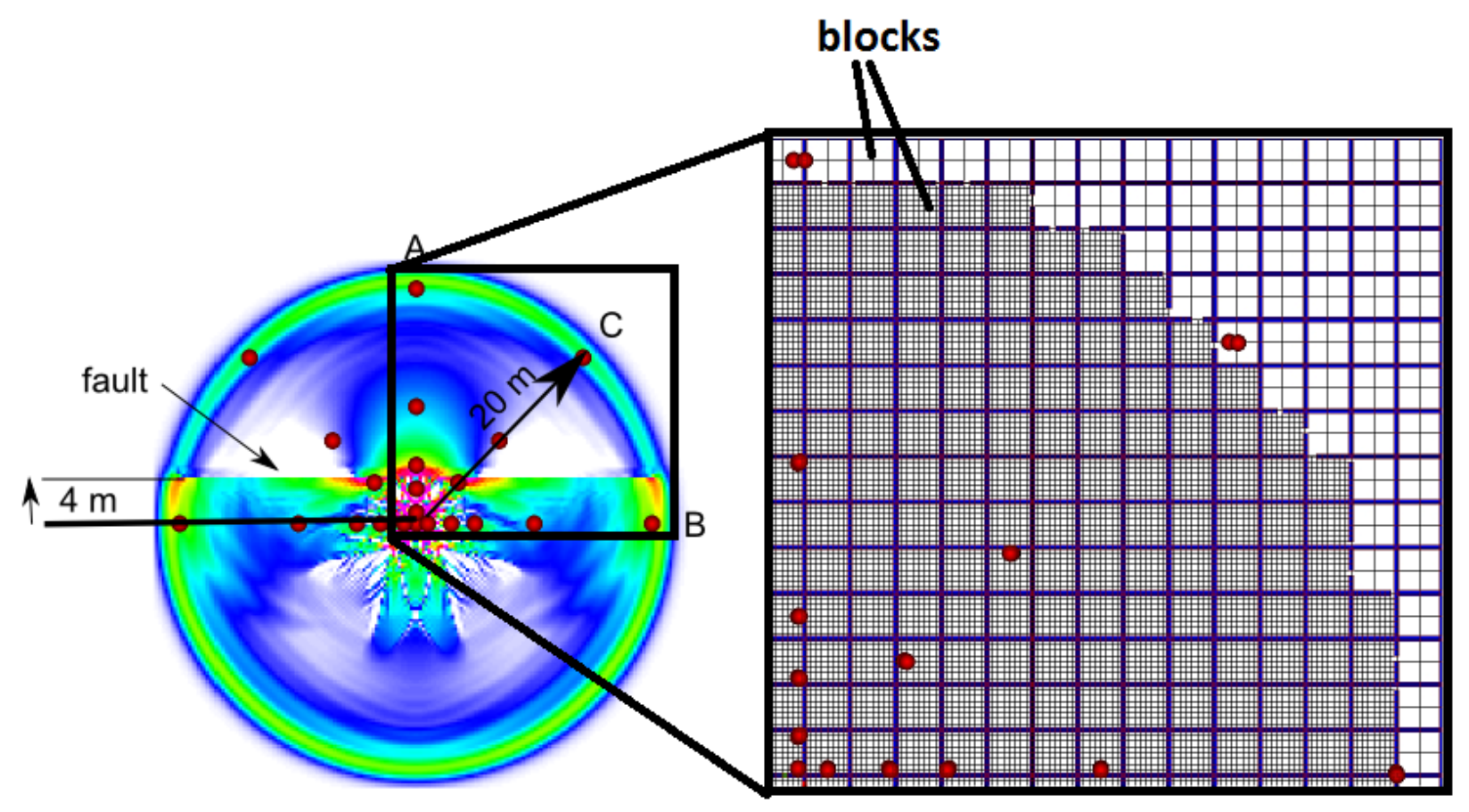

Figure 2 Pressure contours (0-0.1 GPa) at $4 \mathrm{~ms}$ time for a cylindrical explosion in granite with a "painted" fault. Target point locations are shown with red dots, mesh and blocks are shown on the right.

The effect of the fault was studied both for a "painted" fault, in which case it was modeled as a layer of weak material, and as an explicit contact boundary aligned with the mesh. In both cases results were very similar. This gave us the confidence to apply the same technique in significantly more expensive 3D studies. 


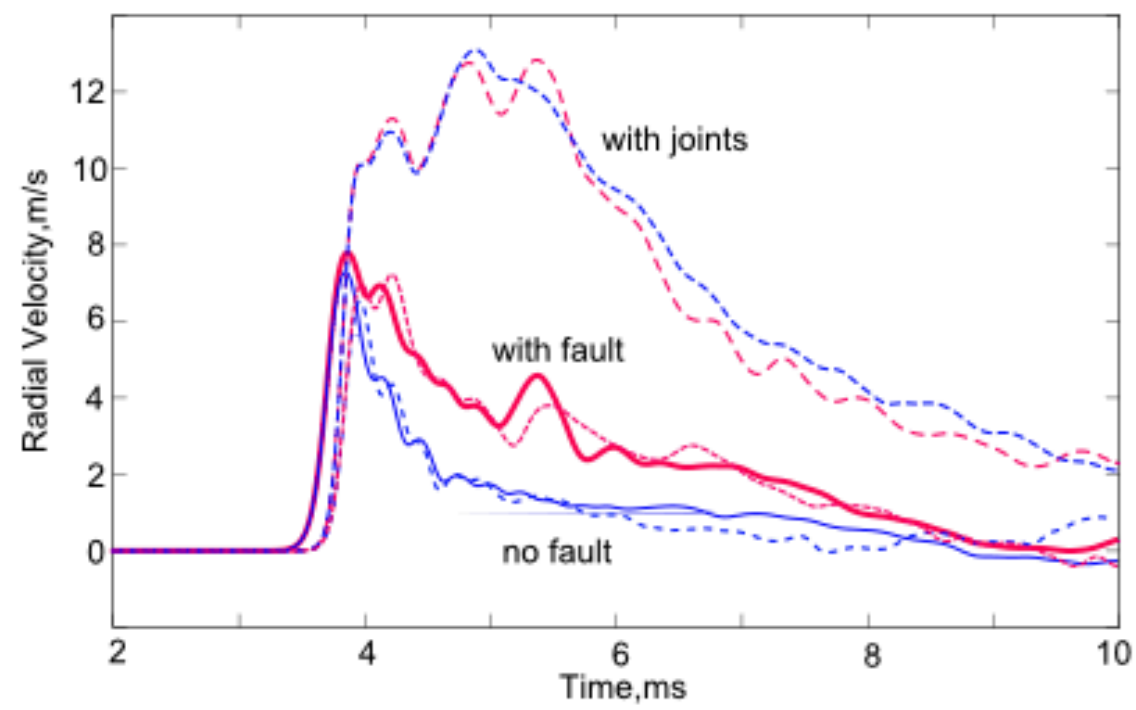

Figure 3 Radial Velocity evolution at point B calculated with and without fault using both discrete and continuum meshes. In calculations with sliding joints $95 \%$ of joints were sliding (friction angle 34 ) and $5 \%$ were cohesive.

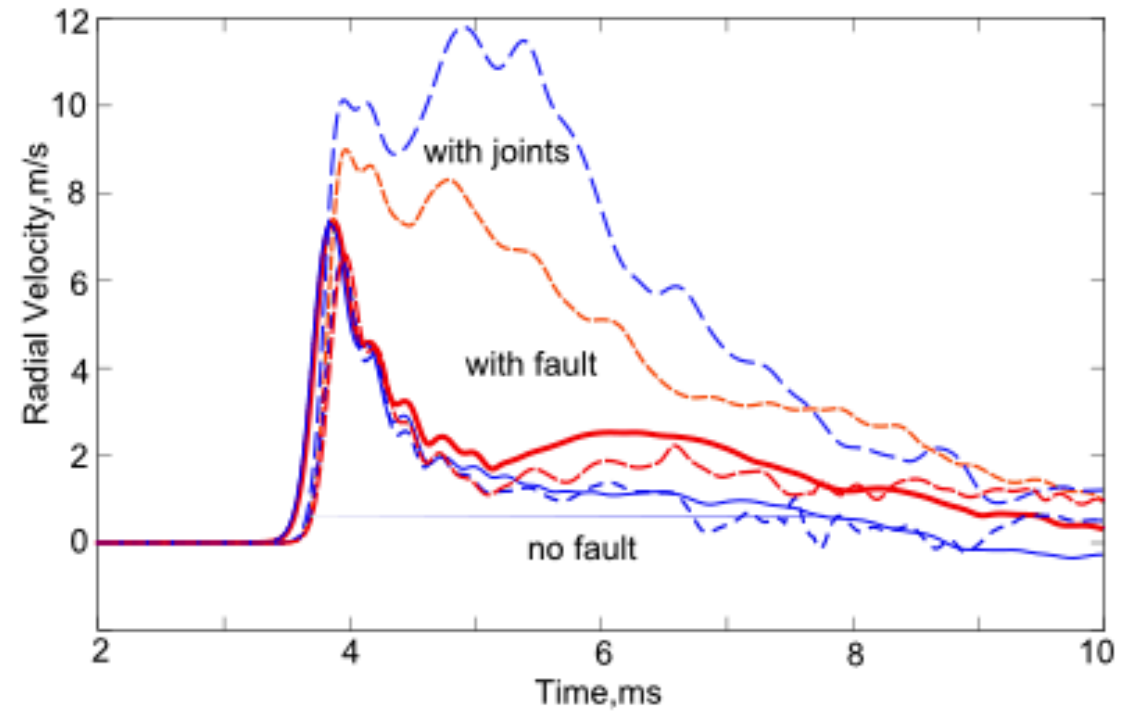

Figure 4 Radial Velocity evolution at point A calculated with and without fault using both discrete (dashed lines) and continuum meshes (solid lines). Top two curves represent discrete calculations with and without (the top curve) fault. 


\section{Three Dimensional Discrete Simulations of the SPE1 Shot (effect of faults)}

Our next series of predictions are fully three dimensional and incorporate the two major faults. The fault data were extracted from the logging data in the emplacement hole and the instrumentation holes where logging data were collected. In the discrete simulations the faults were painted as a $1 \mathrm{~m}$ thick layer of weak material with strongly reduced yield strength. Figure 5 displays the mesh geometry used in 3D.

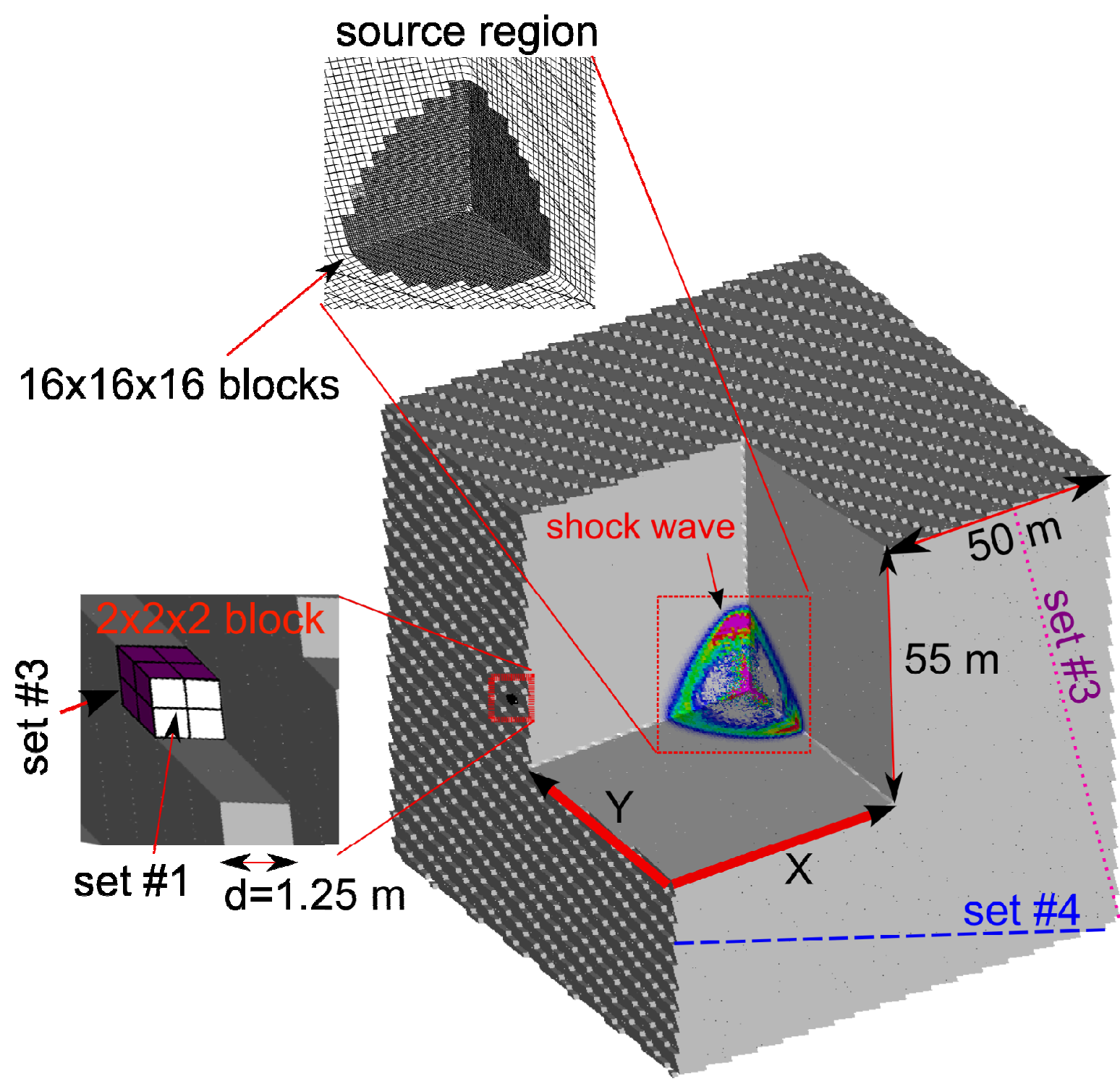

Figure 5 Three dimensional computational model for rock mass formation with $\mathbf{3}$ joint sets. 
A jointed rock formation of $100 \times 100 \times 100 \mathrm{~m}$ size was created by paving the space with parallelepiped blocks as shown in Figure 5. Each block was sub-discretized by a number of elements, with $16 \times 16 \times 16$ elements used in the source region and $2 \times 2 \times 2$ elements used elsewhere. The contacts were set at the exterior faces. The properties of the contacts were varied randomly from sticky to sliding with low frictional coefficient to satisfy a given joint persistency. This approach allowed us to describe a joint system with three main joint sets. Energy equivalent to $100 \mathrm{~kg}$ of TNT was released instantaneously in an idealized spherical source region of the same size $(R=267 \mathrm{~mm})$ as in the SPE.

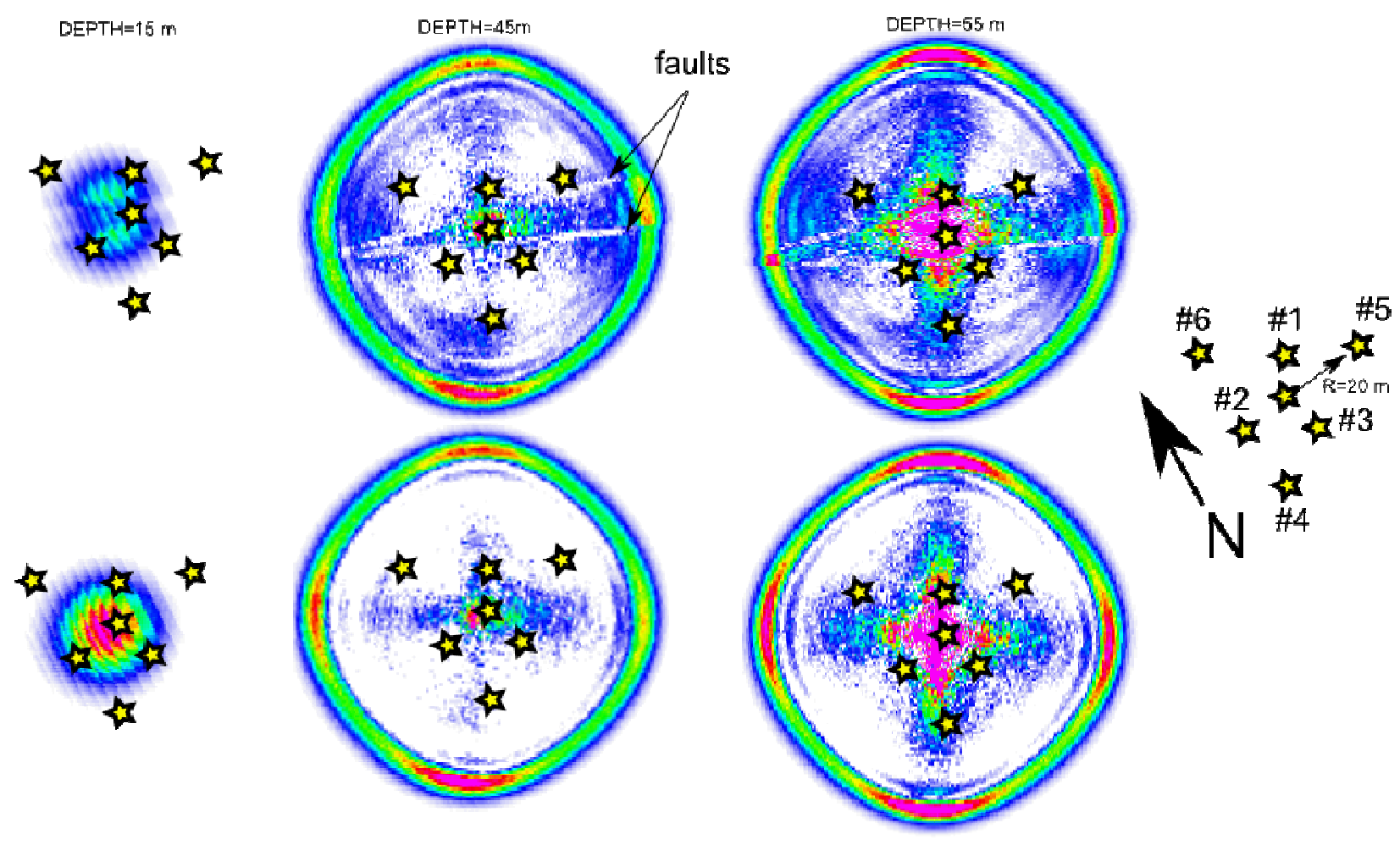

Figure 6 Pressure contour in horizontal planes at 3 different depths $(z=-15 \mathrm{~m}$, pressure range 0-1 MPa; $\mathrm{z}=-45 \mathrm{~m}$, and $z=-55 \mathrm{~m}$, pressure range $0-2 \mathrm{MPa}$ ) calculated with and without faults for time $9 \mathrm{~ms}$. Locations of the vertical holes are shown with stars at ranges $10 \mathrm{~m}$ and $20 \mathrm{~m}$, as is the location of the source). Effective friction angle for the joints was 12 degrees. 


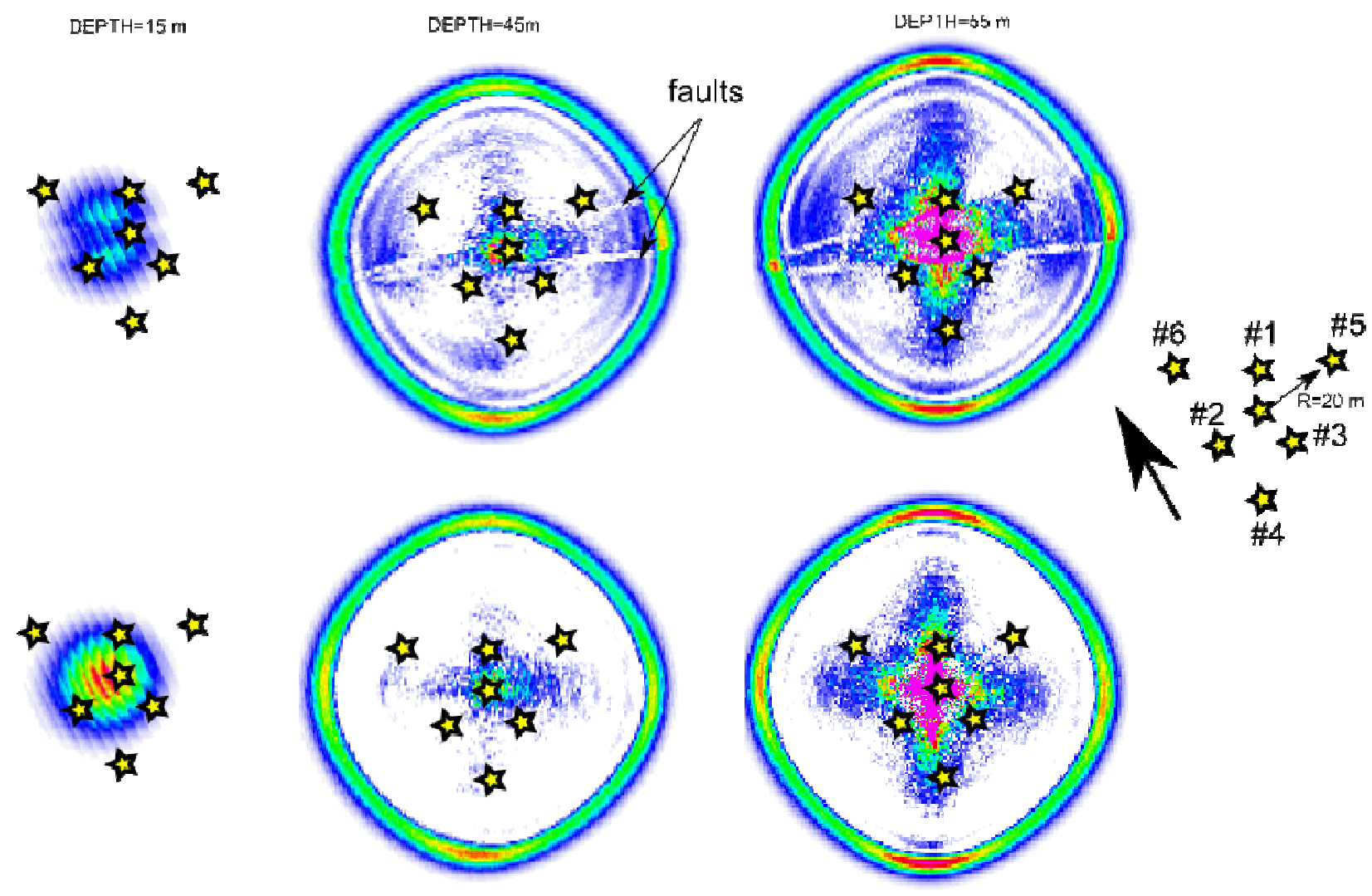

Figure 7 Pressure contour in horizontal planes at 3 different depths $(z=-15 \mathrm{~m}$, pressure range 0-1 MPa; $z=-45 \mathrm{~m}$, and $\mathrm{z}=-55 \mathrm{~m}$, pressure range 0-2 $\mathrm{MPa}$ ) calculated with and without faults for time $9 \mathrm{~ms}$. Locations of the vertical holes are shown with stars at ranges $10 \mathrm{~m}$ and $20 \mathrm{~m}$, as is as the location of the source I ). Effective friction angle for the joints was 22 degrees.

The results of our discrete simulations, displayed in Figure 8, indicate that joints may induce a large amount of anisotropy. Pressure contours calculated at three different planes where the measurements were taken are shown in Figure 6 and Figure 7 for time $=9 \mathrm{~ms}$, both with and without faults. It is seen that gauges 1 and 4 are located in directions favorable for wave propagation, while motion in directions of gauges 2 and 5 is suppressed due to sliding at the joints. It is interesting to note that, at $15 \mathrm{~m}$ depth, the wave arrives first on the left side from the source. Such wave deformation in the vertical direction is caused by joint set 3 which favors wave propagation along the joint plane inclined to the left, as shown in Figure 5 or in normal to the joint direction, which explains why at $45 \mathrm{~m}$ level the pressure is high on the right. Figure 8 shows that there is a significant variation in attenuation of radial velocity in the horizontal plane at $55 \mathrm{~m}$ (explosion depth) at ranges of 10 and $20 \mathrm{~m}$ and at ranges of $14 \mathrm{~m}$ and 
$22 \mathrm{~m}$ for the stations located at $150 \mathrm{ft}$ depth. This can be explained by the sliding that occurs at the joints and is confirmed by the discrete calculations. Both the discrete calculations performed with GEODYN-L and the experiments show significant scatter in peak velocity and peak displacement values measured at the same range at different azimuths, which indicates that the joints have a profound effect on the wave anisotropy and can help explain the experimental observations. Figure 8 shows radial velocity histories calculated at $20 \mathrm{~m}$ (top right corner) for both dry and wet joints. As in the experiment, the peak velocities are different at various azimuths corresponding to locations \#4 and \#6. Reduced friction corresponding to wet joints increases this difference. Similar to the calculations, the highest velocity was measured at locations \#1 $(R=10 \mathrm{~m})$ and \#4 $(R=20 \mathrm{~m})$. Preliminary results indicate that both peak veloc ity and displacement increase when more joints are added. The results show that taking joints into consideration dramatically changes the wave forms

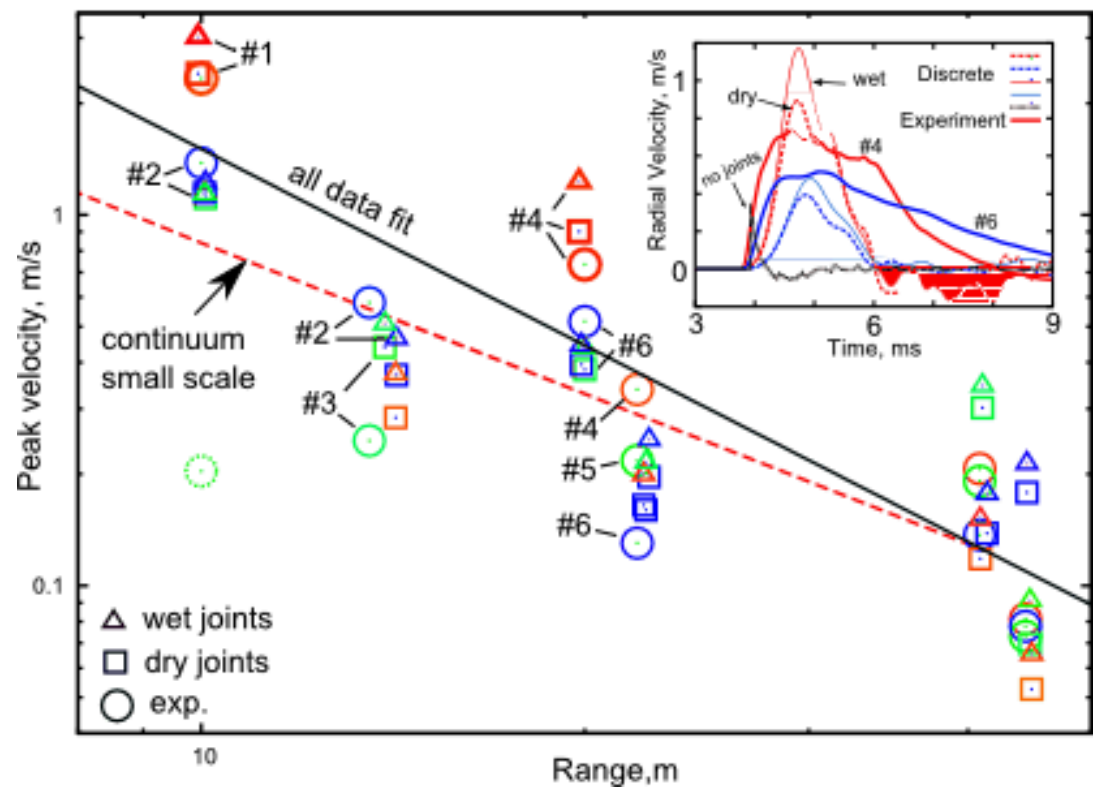

Figure 8 Peak radial velocity measured in experiment (circles) and calculated, both using the small scale continuum model (dashed line) and the discrete model (triangles and squares). The solid line shows the nuclear explosion data fit.

Faults do not seem to have a big effect on the waveforms. Figure 9 and 
Figure 10 show radial velocities calculated at stations located at the source level, both with (bold lines) and without (thin lines) the fault. The biggest effect is observed for station \#6. The faults here were modeled as a $1 \mathrm{~m}$ thick layer of material with a constant low strength. Further analysis of the fault role for SPE was performed with the aid of our Eulerian hydrocode, GEODYN, described in the following section of this report. Fault modeling in GEODYN was based on the level set approach, which has proven to yield results comparable to those obtained with the explicit Lagrangian model used in GEODYN-L for very stiff non-complaint joints (see Lomov et al 2009).

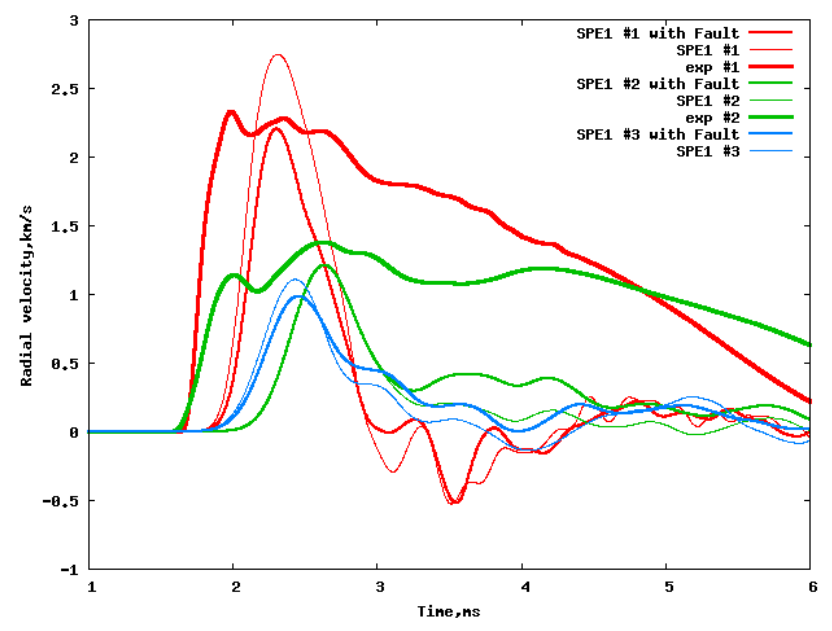

Figure 9 Radial velocities calculated for SPE1 with (bolder line) and without (thinner line) painted faults at ranges $10 \mathrm{~m}$.

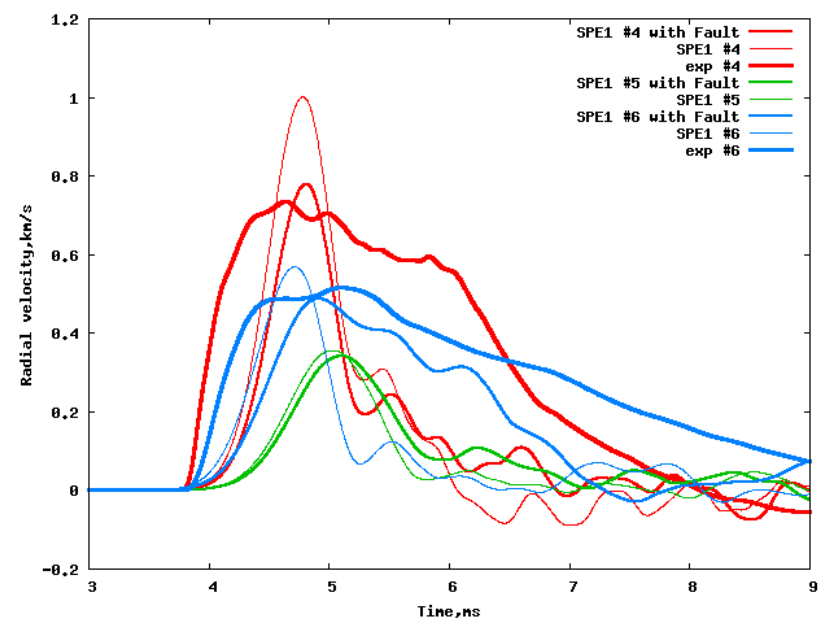


Figure 10 Radial velocities calculated for SPE1 with (bolder line) and without (thinner line) painted faults at ranges $20 \mathrm{~m}$.

\section{Continuum 3D Simulations of the SPE2 shot}

We performed simulations with GEODYN to assess the effect of the two faults in the SPE 2 testbed on the observed wave motion in the near field. Two different types of representations of the faults were used in the simulations: 1 ) the two faults were represented as a weak granite material relative to the surrounding bedrock; 2) the two faults were modeled as frictional surfaces where the two sides are allowed to have discontinuous shear motions against each other. Figure 11 shows the borehole stations (triangles) at the SPE2 shot depth. It is noted that stations \#2 and \#3 are both behind fault \#2 (solid green line) and the source-station \#1 path is nearly perpendicular to the fault \#1 surface.

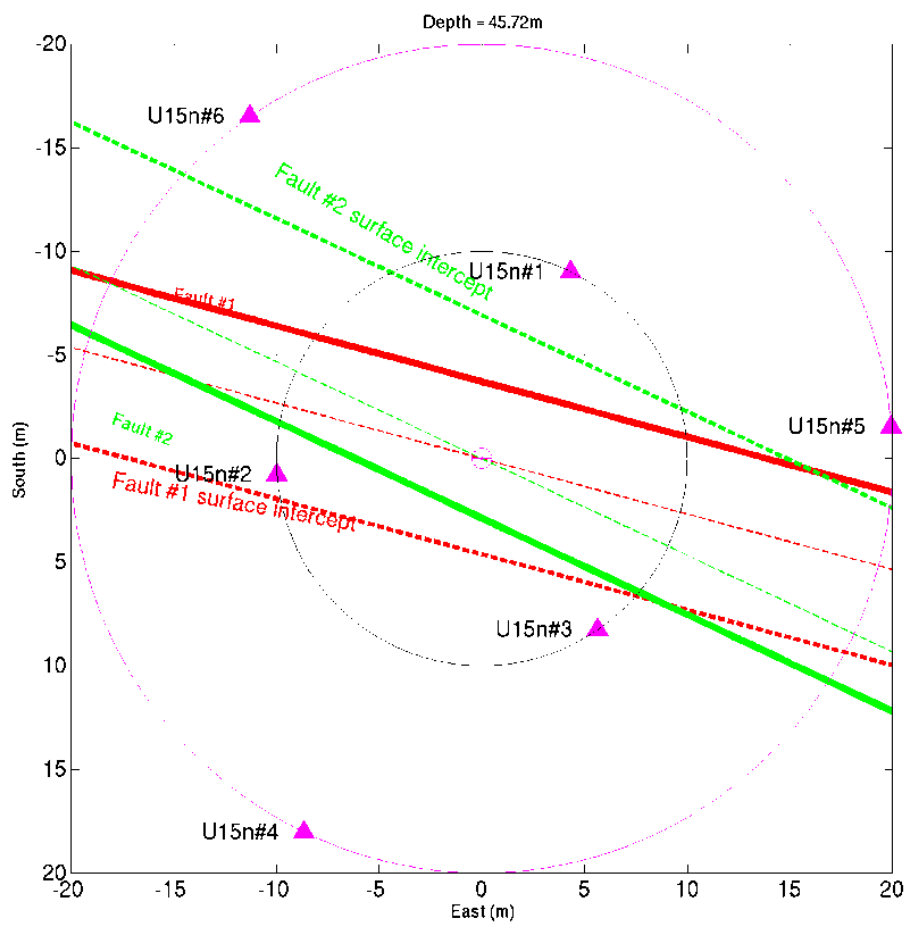

Figure 11 Diagram of the two faults (fault \#1: red solid line, fault \#2: green solid line) at the SPE2 shot depth. The 6 borehole stations are marked with pink triangles. It is noted that the two stations \#2 and \#3 are behind fault \#2 and source-station \#1 line is almost perpendicular to fault \#1. 
In the simulations, the SPE2 source was modeled as an ANFO explosive and the JWL equation was used. The depth is $150 \mathrm{ft}$.

A total of 5 calculations were performed as follows to investigate the effects of the two faults:

1) calculation without the faults (solution 1 , background solution)

2) using a weak material to represent the faults (solution 2)

3) using the level set method to represent the interface and zero friction angle ( $\mu=0$, pure slip surface condition, solution 3 ). This is an extreme case which is designed to show the upper bound effects of the two faults.

4) using the level set method to represent the interface with friction angle of 20 degrees ( $\mu=0.36$, solution 4$)$. Shear experiments show that friction angles are greater than 22 degrees so this calculation is close to the realistic observed friction. (In fact the results below show the effect of the two faults is quite minimal at this angle).

5) 2D cylindrical calculation for comparison (solution 5). 

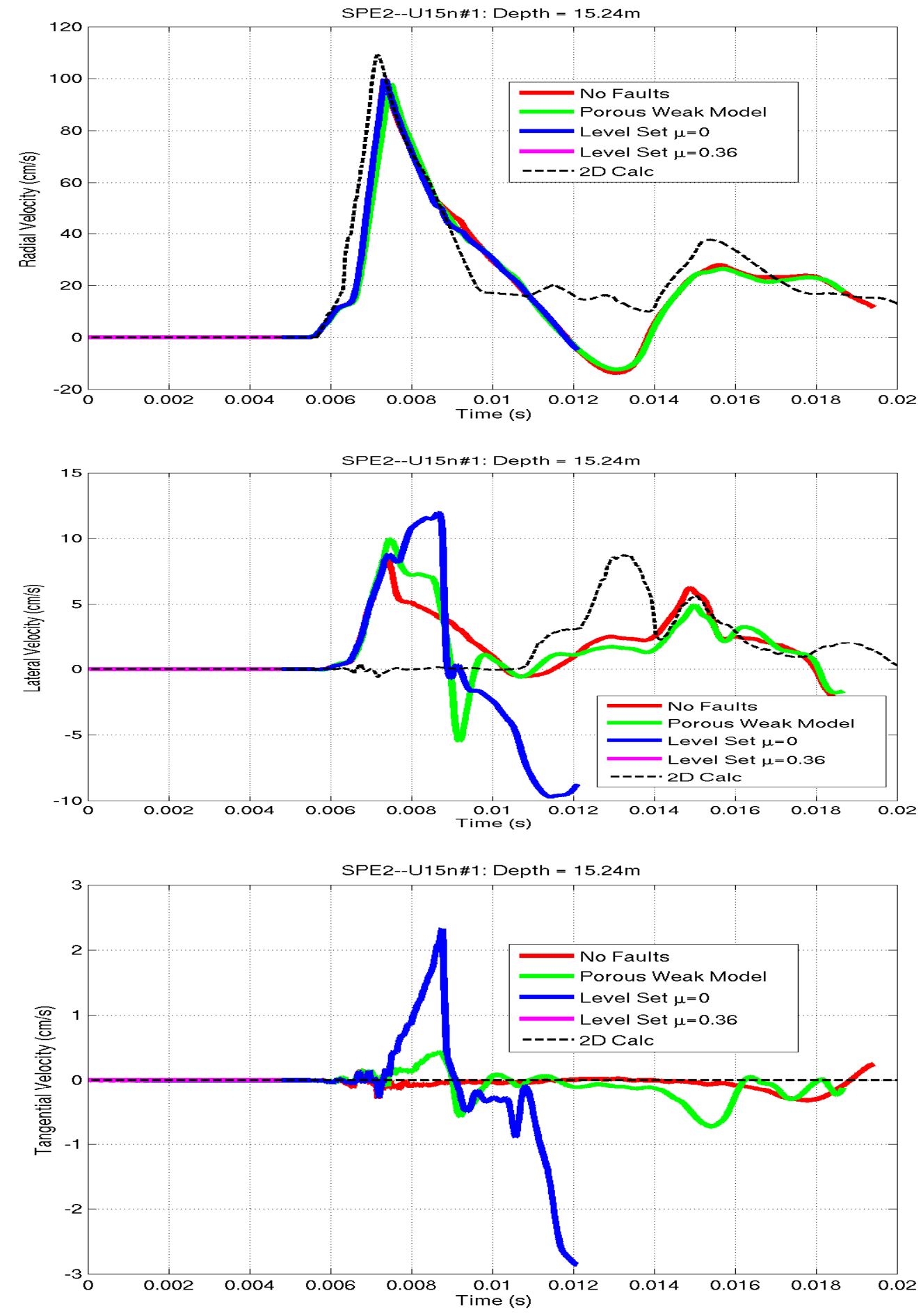

Figure 12 Predicted velocity histories in borehole U15n\#1 at a depth of 50ft. 

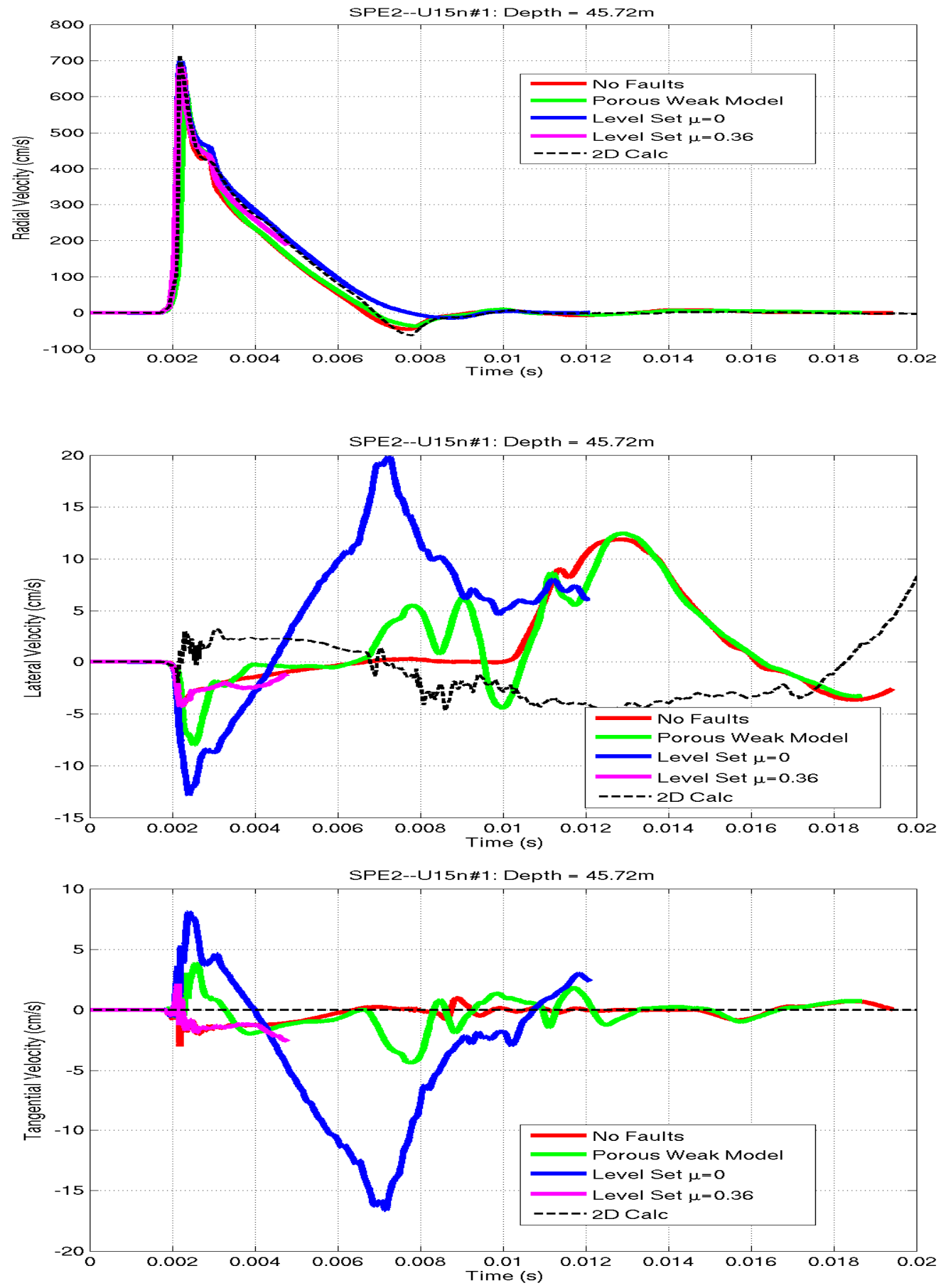

Figure 13 Predicted velocity histories in borehole U15n\#1 at a depth of $150 \mathrm{ft}$. 

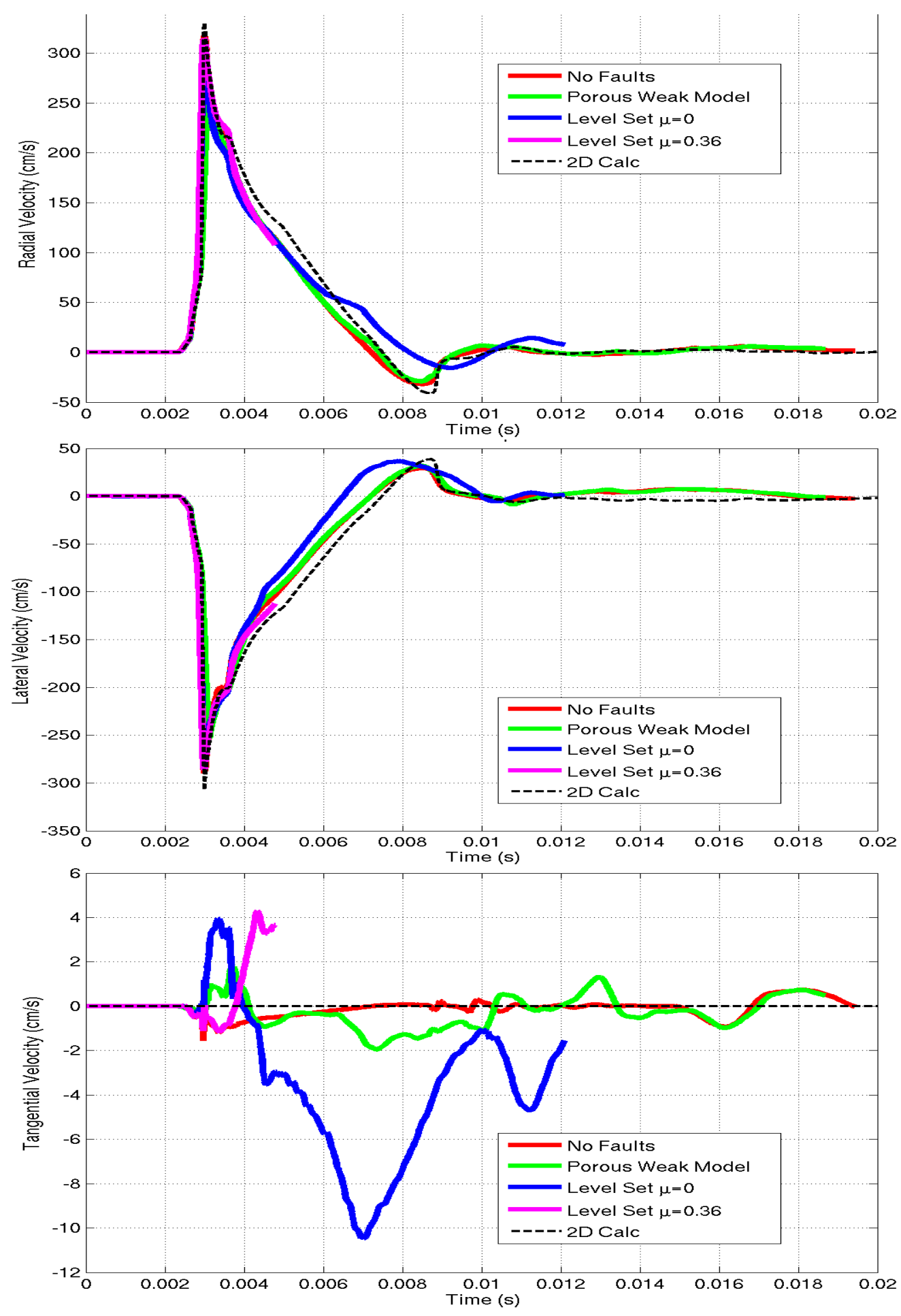

Figure 14 Predicted velocity histories in borehole U15n\#1 at a depth of $180 \mathrm{ft}$. 

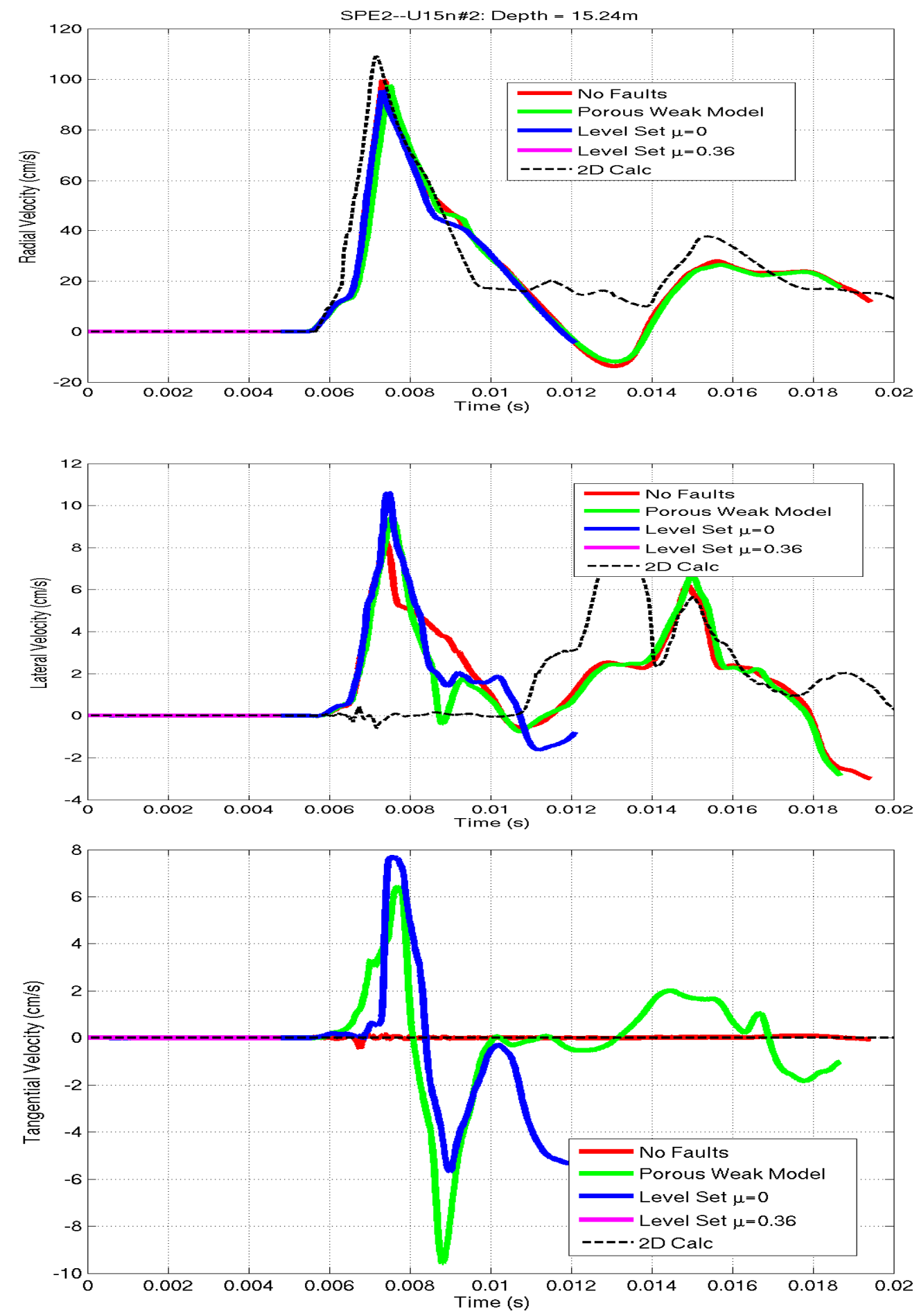

Figure 15 Predicted velocity histories in borehole U15n\#2 at a depth of $50 \mathrm{ft}$. 

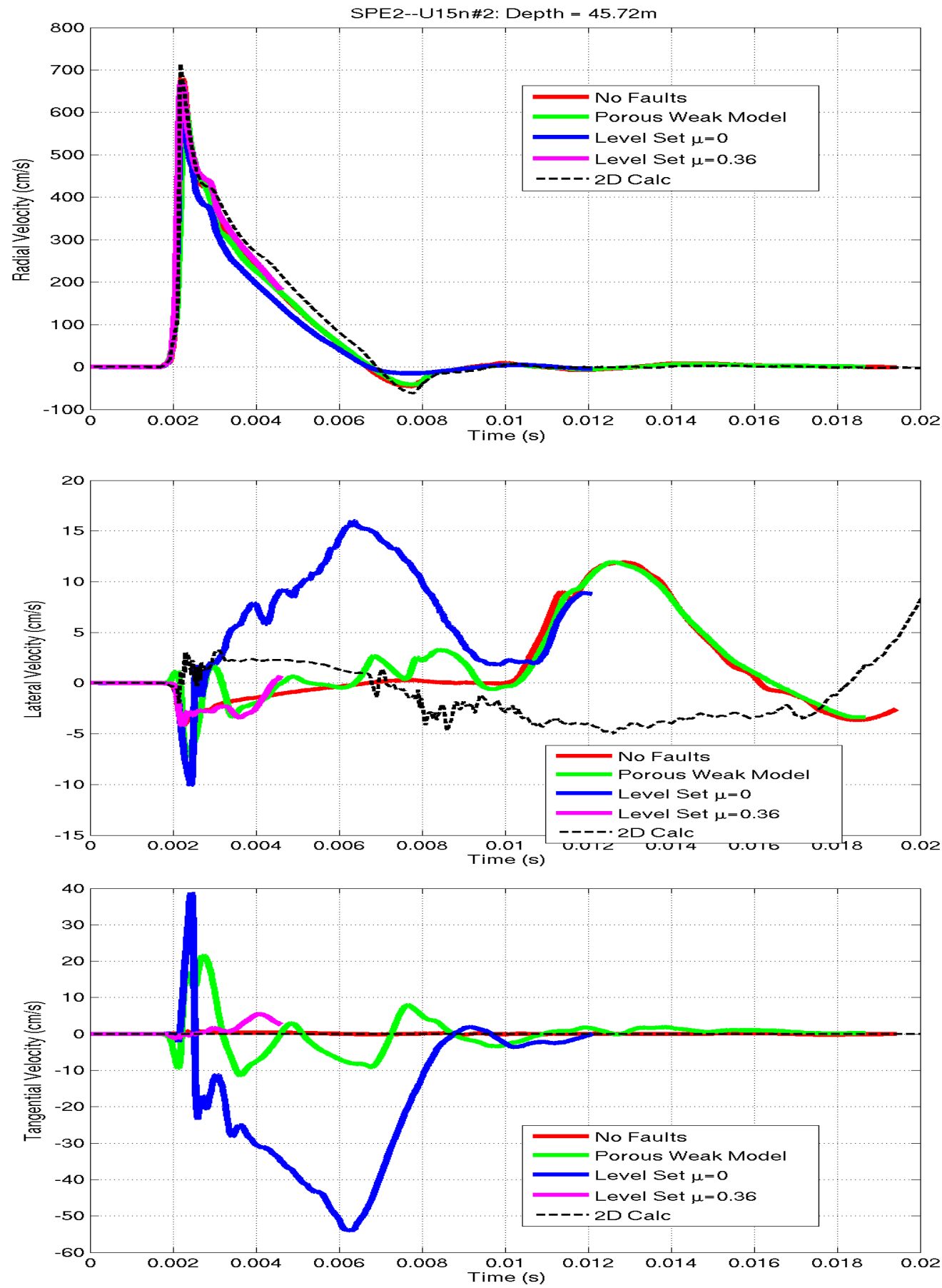

Figure 16 Predicted velocity histories in borehole U15n\#2 at a depth of $150 \mathrm{ft}$. 

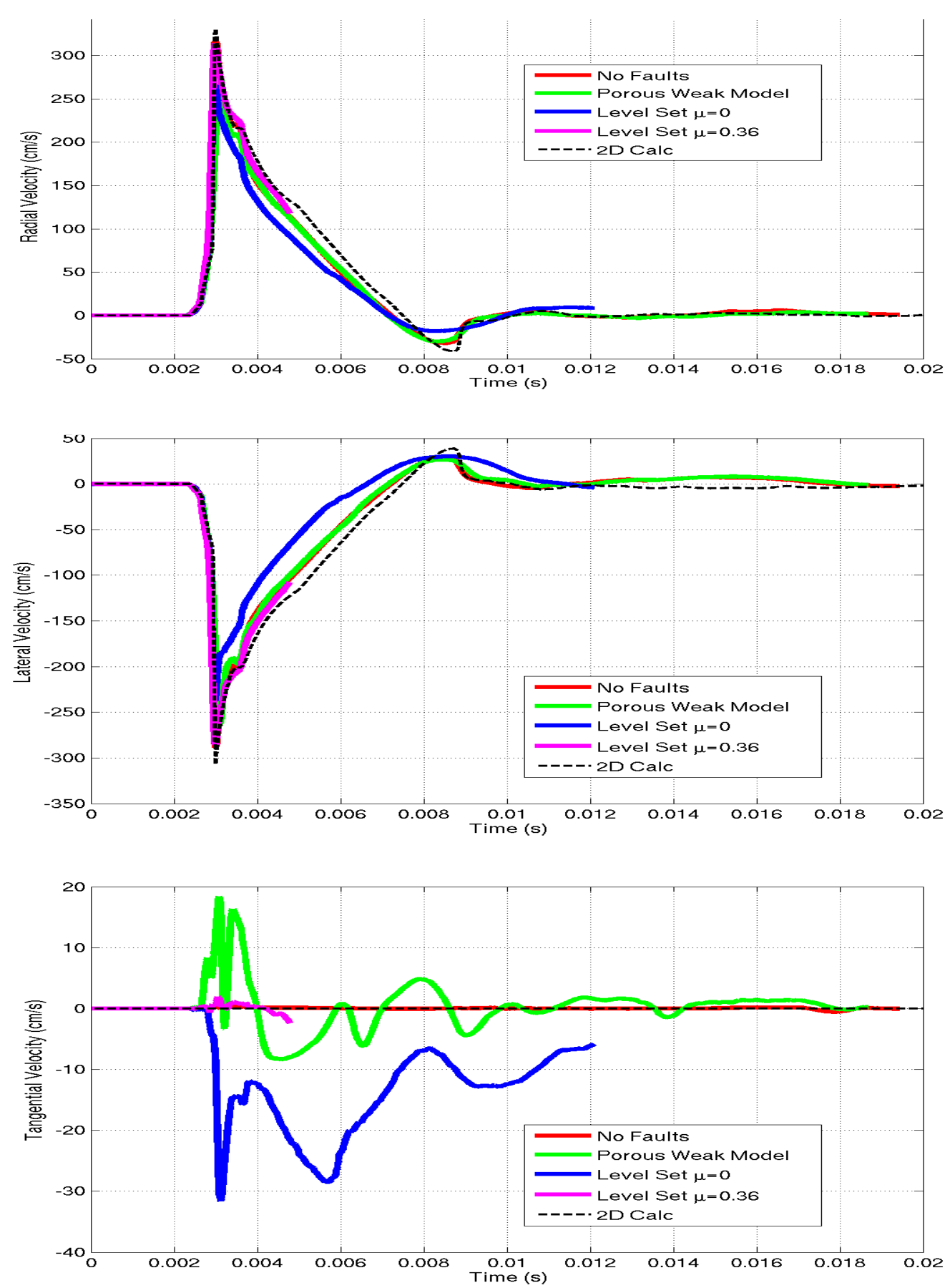

Figure 17 Predicted velocity histories in borehole U15n\#2 at a depth of $180 \mathrm{ft}$. 

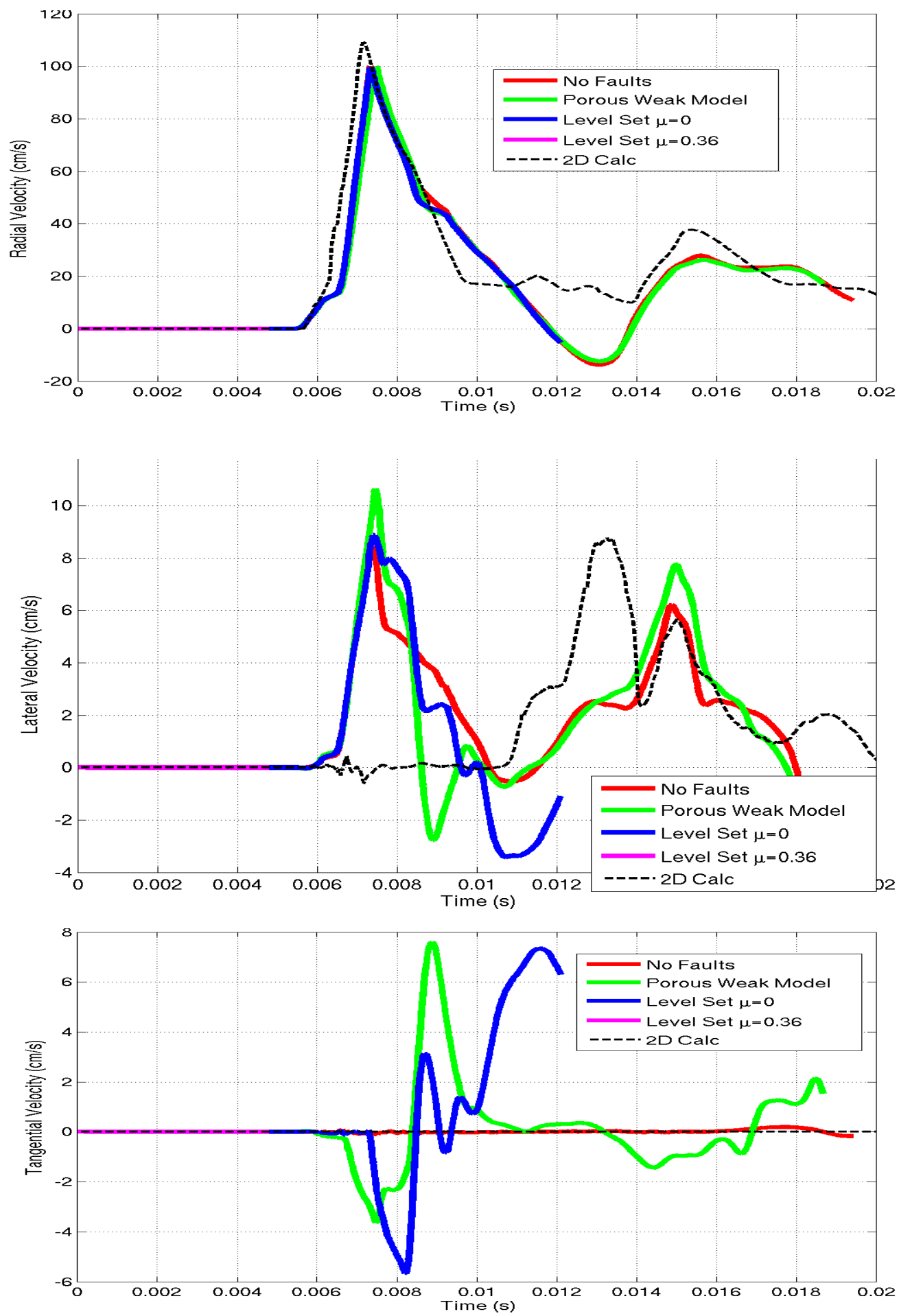

Figure 18 Predicted velocity histories in borehole U15n\#3 at a depth of $50 \mathrm{ft}$. 

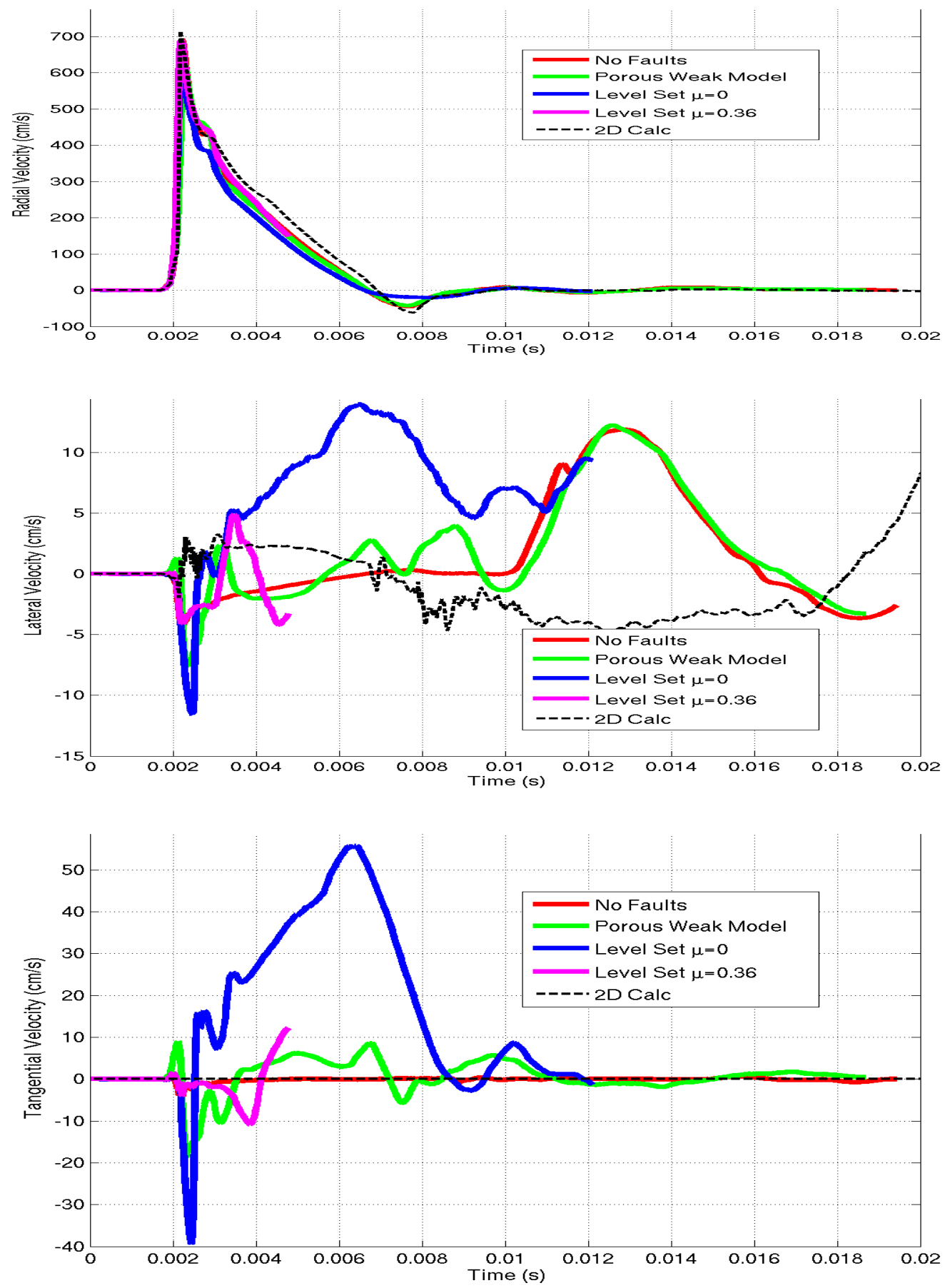

Figure 19 Predicted velocity histories in borehole U15n\#3 at a depth of $150 \mathrm{ft}$. 

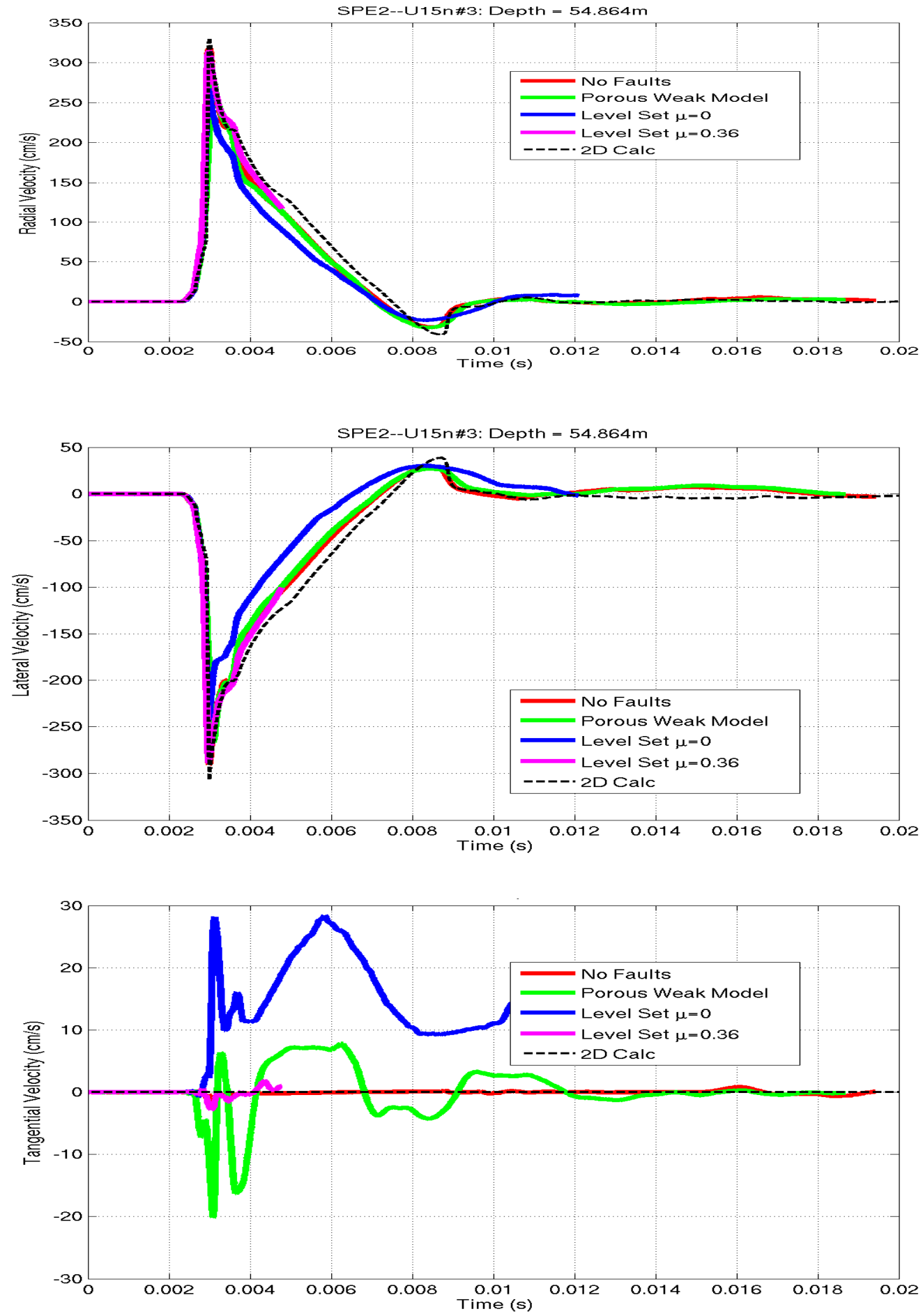

Figure 20 Predicted velocity histories in borehole U15n\#3 at a depth of $180 \mathrm{ft}$. 

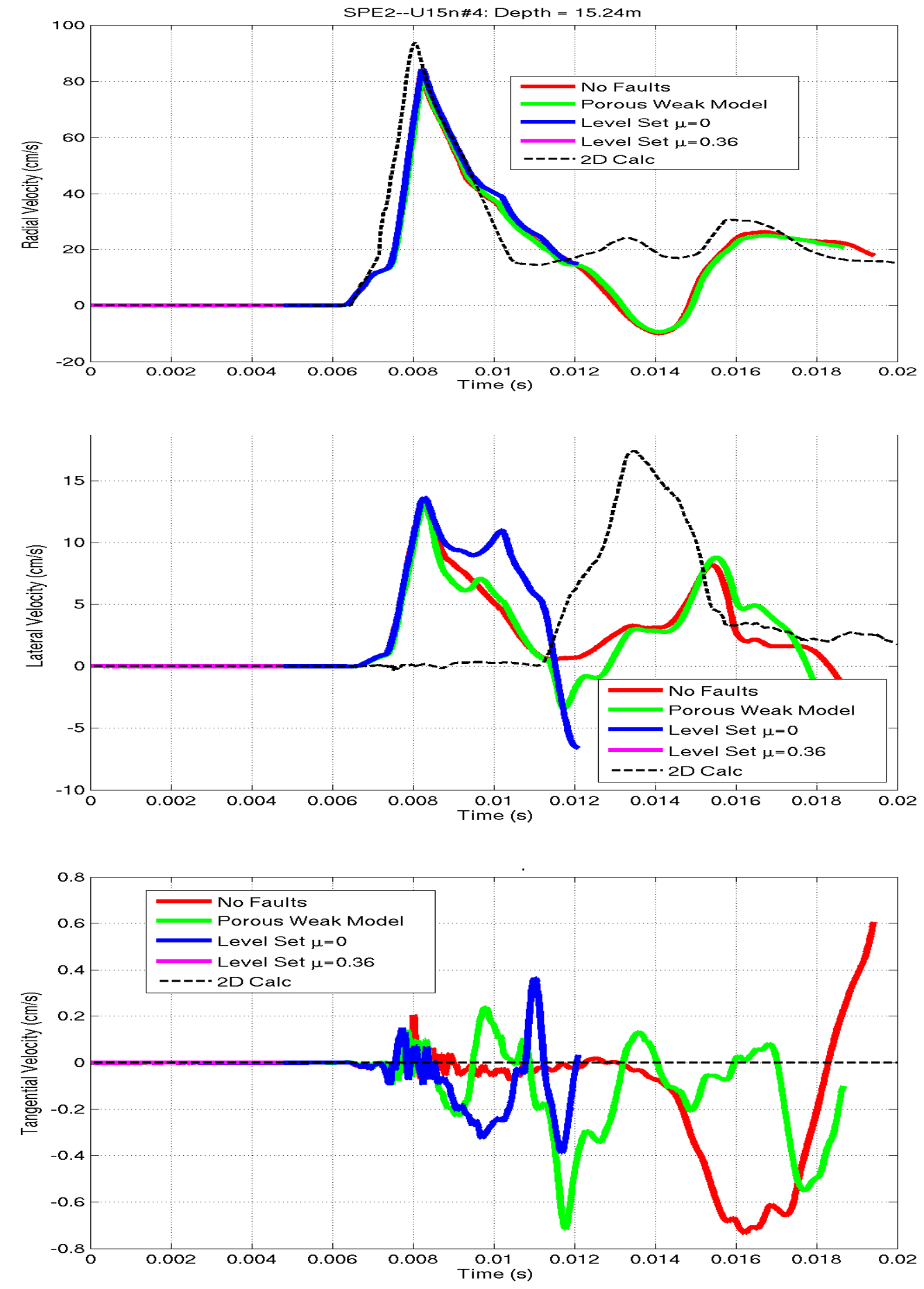

Figure 21Predicted velocity histories in borehole U15n\#4 at a depth of $50 \mathrm{ft}$. 

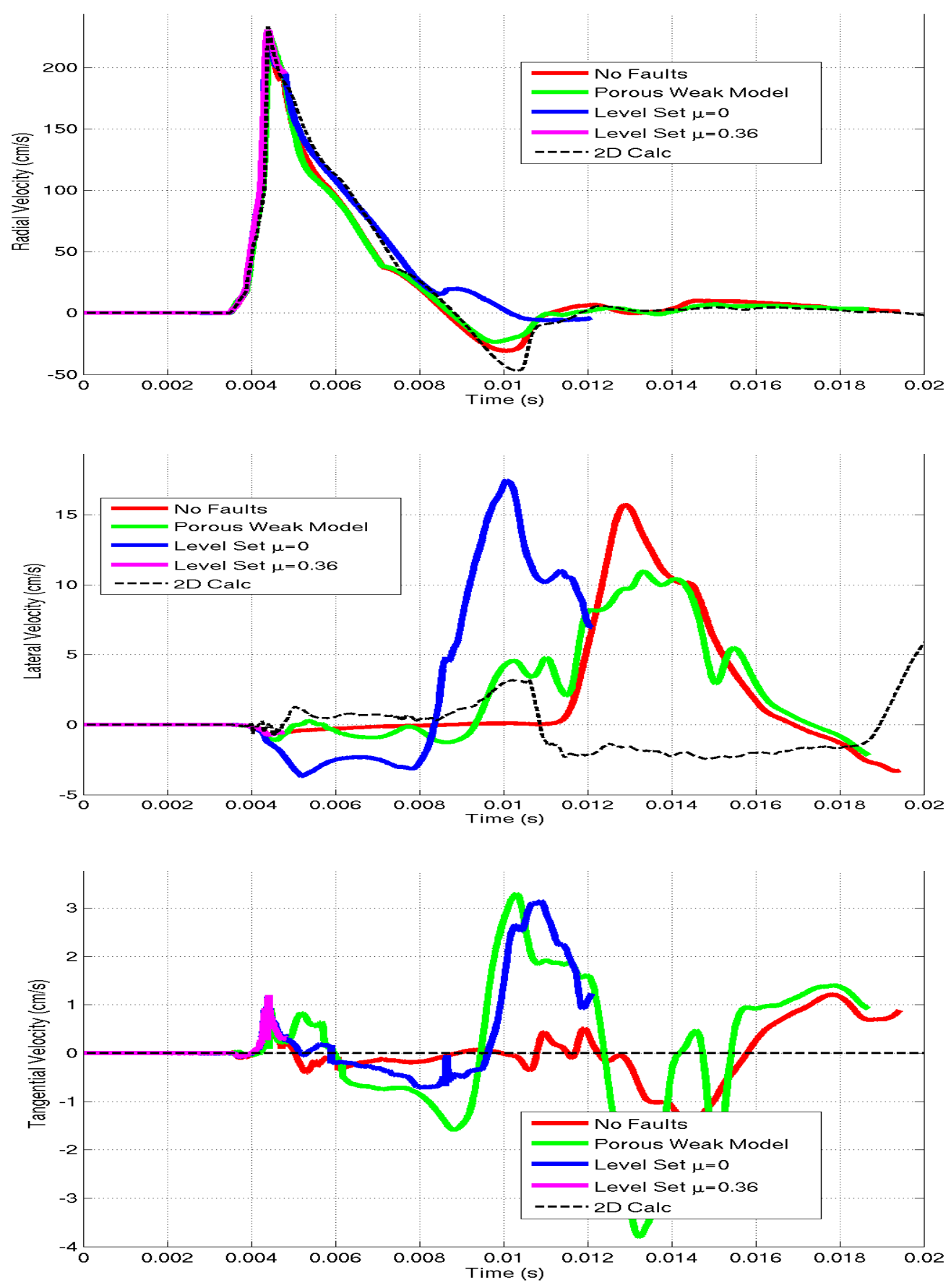

Figure 22 Predicted velocity histories in borehole U15n\#4 at a depth of $150 \mathrm{ft}$. 

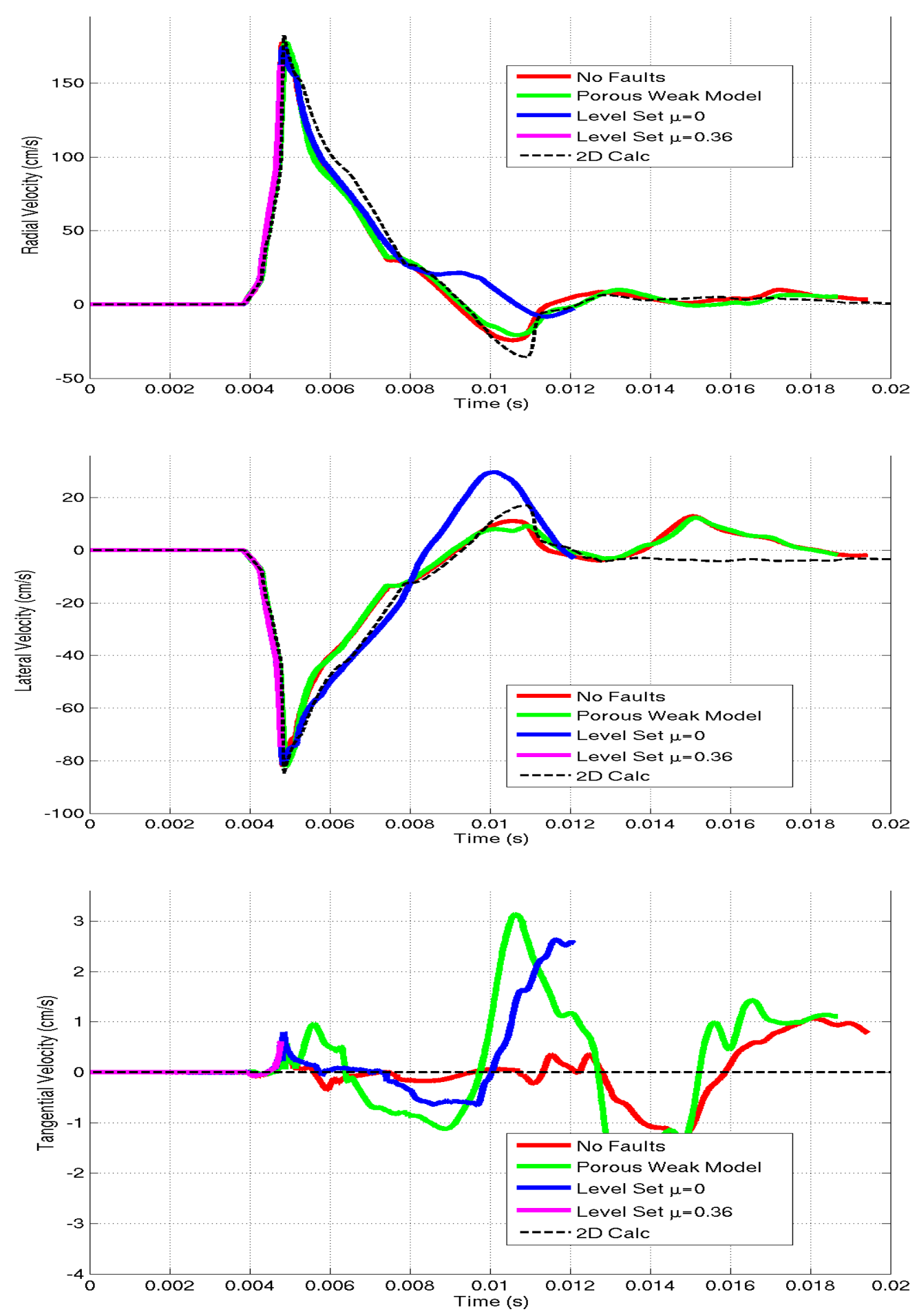

Figure 23 Predicted velocity histories in borehole U15n\#4 at a depth of $180 \mathrm{ft}$. 

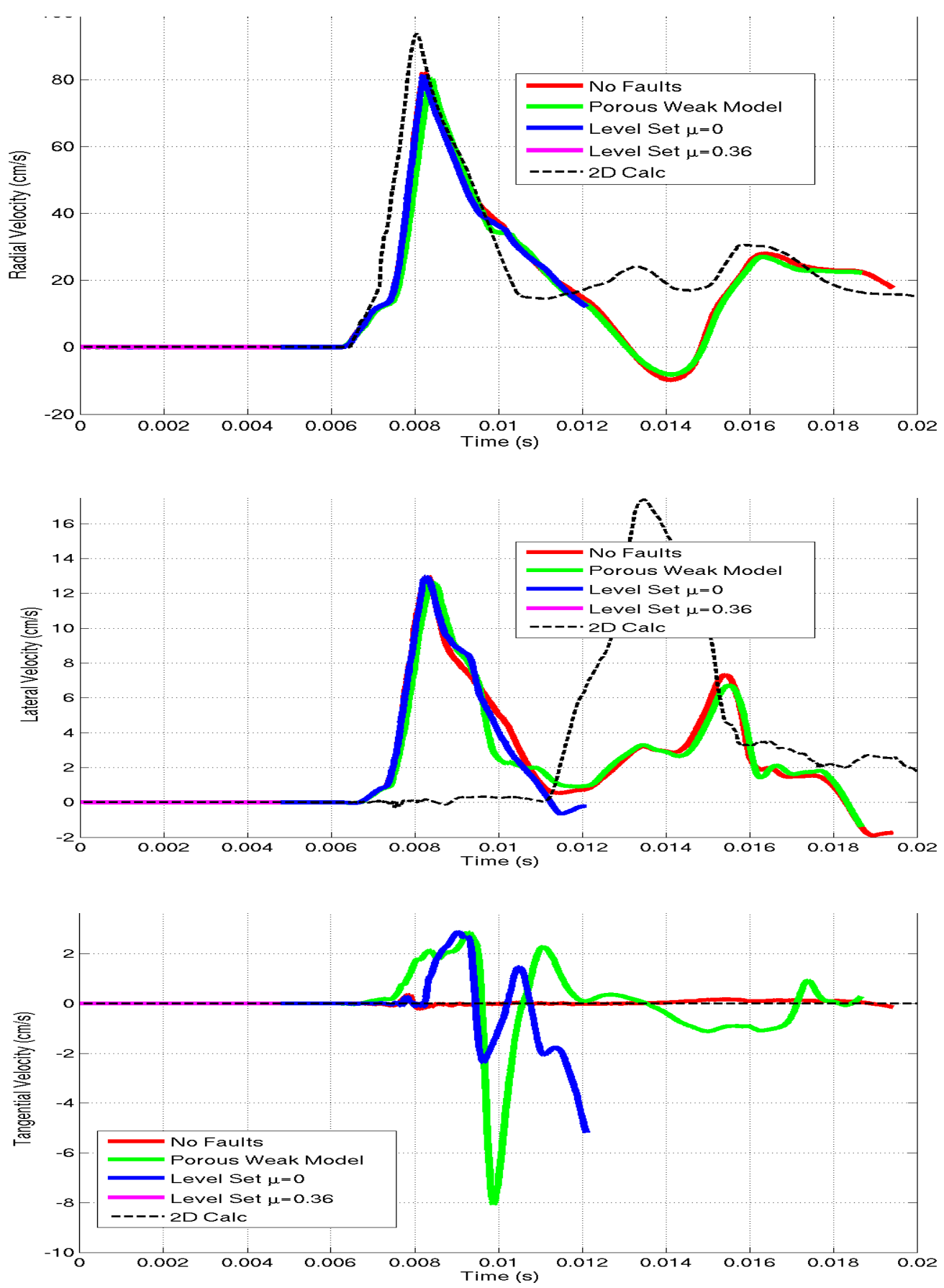

Figure 24 Predicted velocity histories in borehole U15n\#5 at a depth of $50 \mathrm{ft}$. 

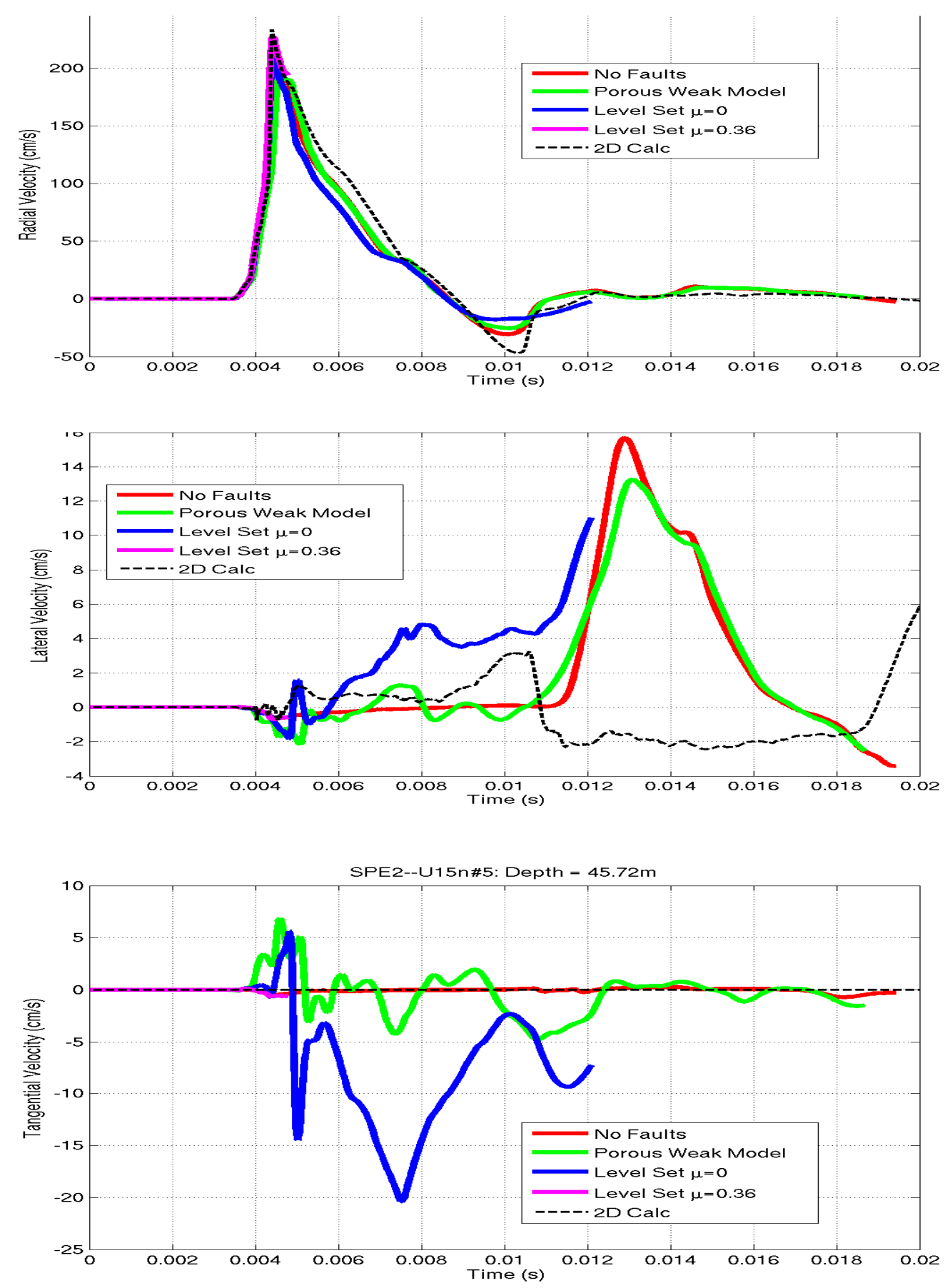

Figure 25 Predicted velocity histories in borehole U15n\#5 at a depth of $150 \mathrm{ft}$. 

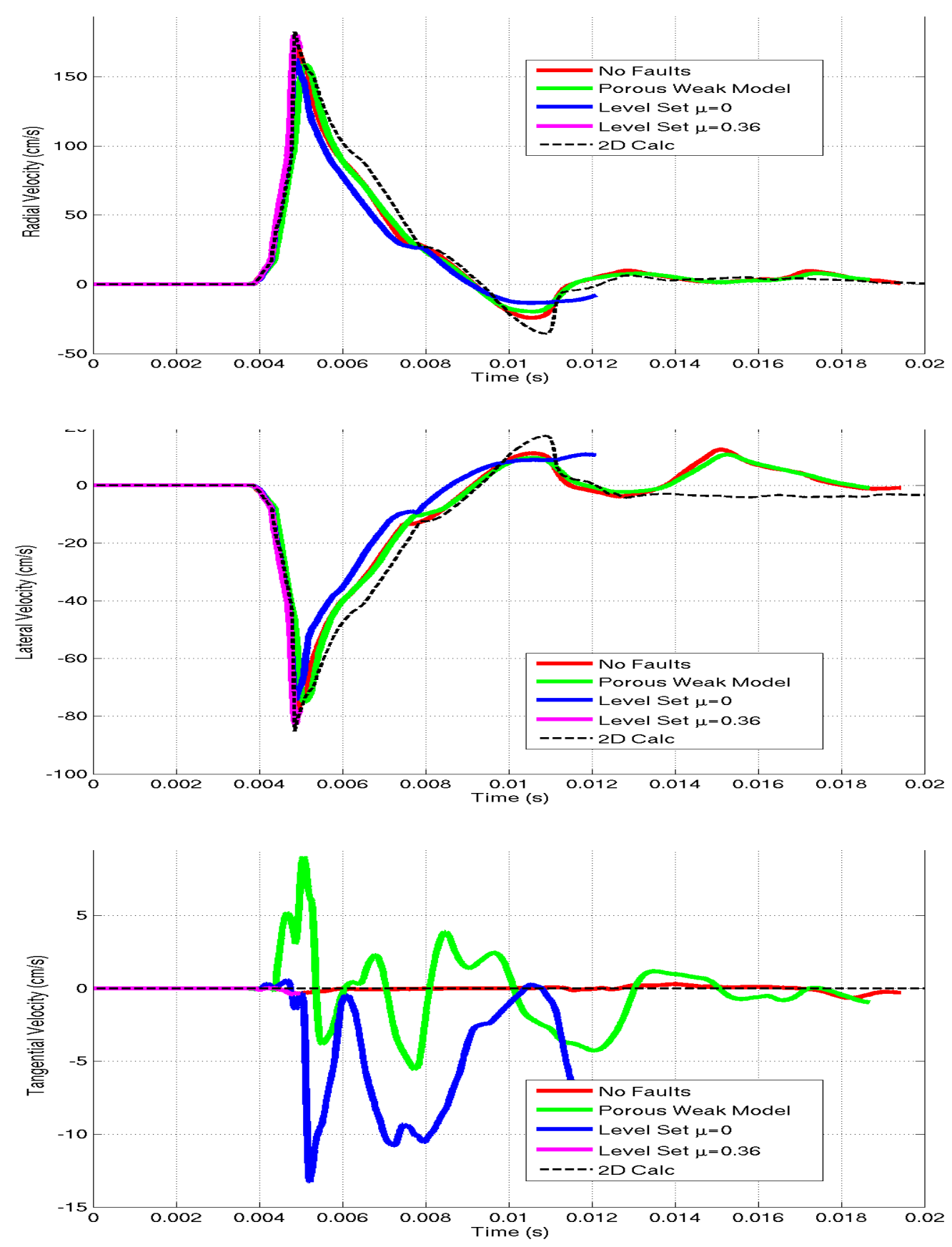

Figure 26 Predicted velocity histories in borehole U15n\#5 at a depth of $180 \mathrm{ft}$. 

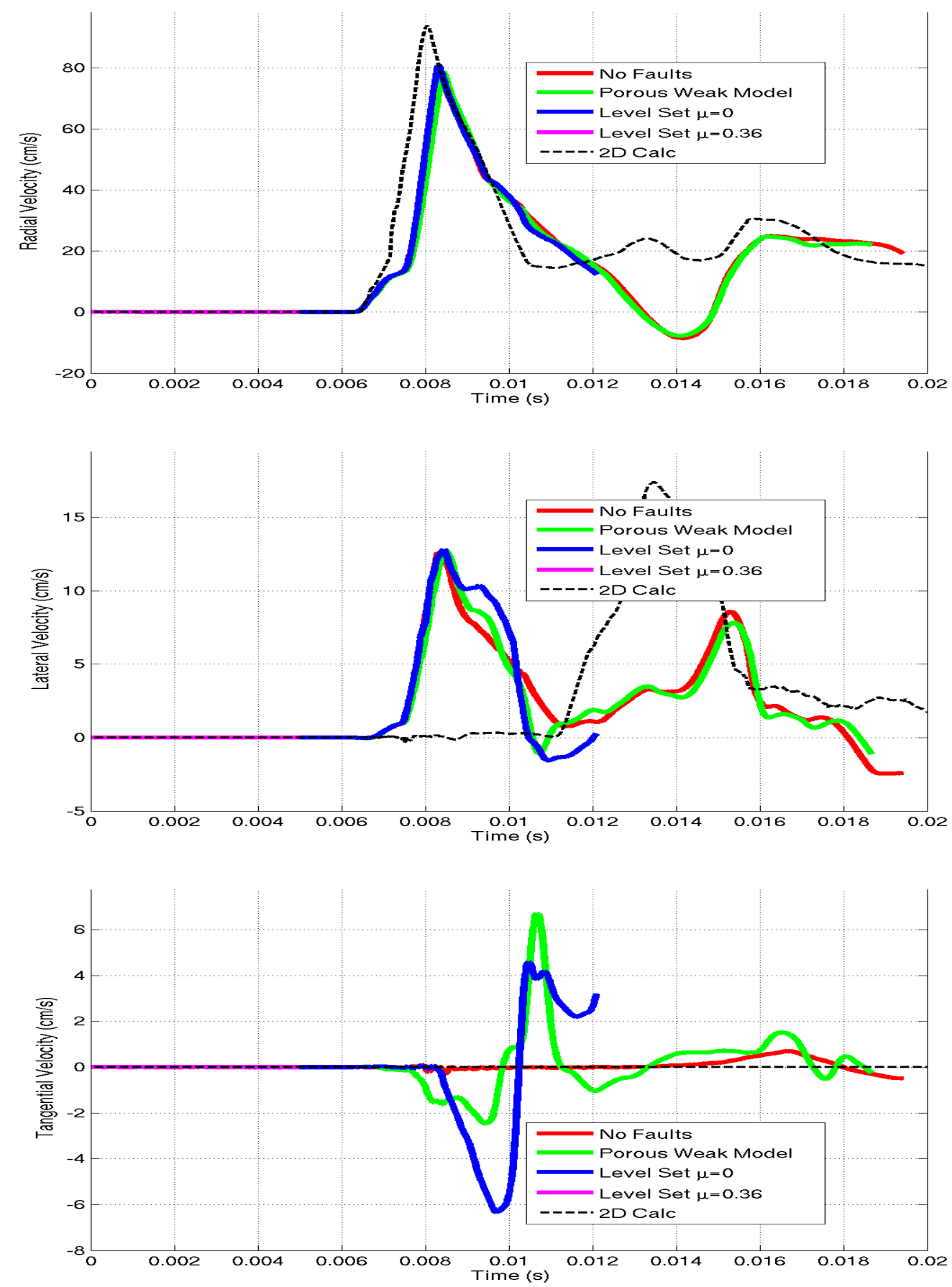

Figure 27 Predicted velocity histories in borehole U15n\#6 at a depth of $50 \mathrm{ft}$. 

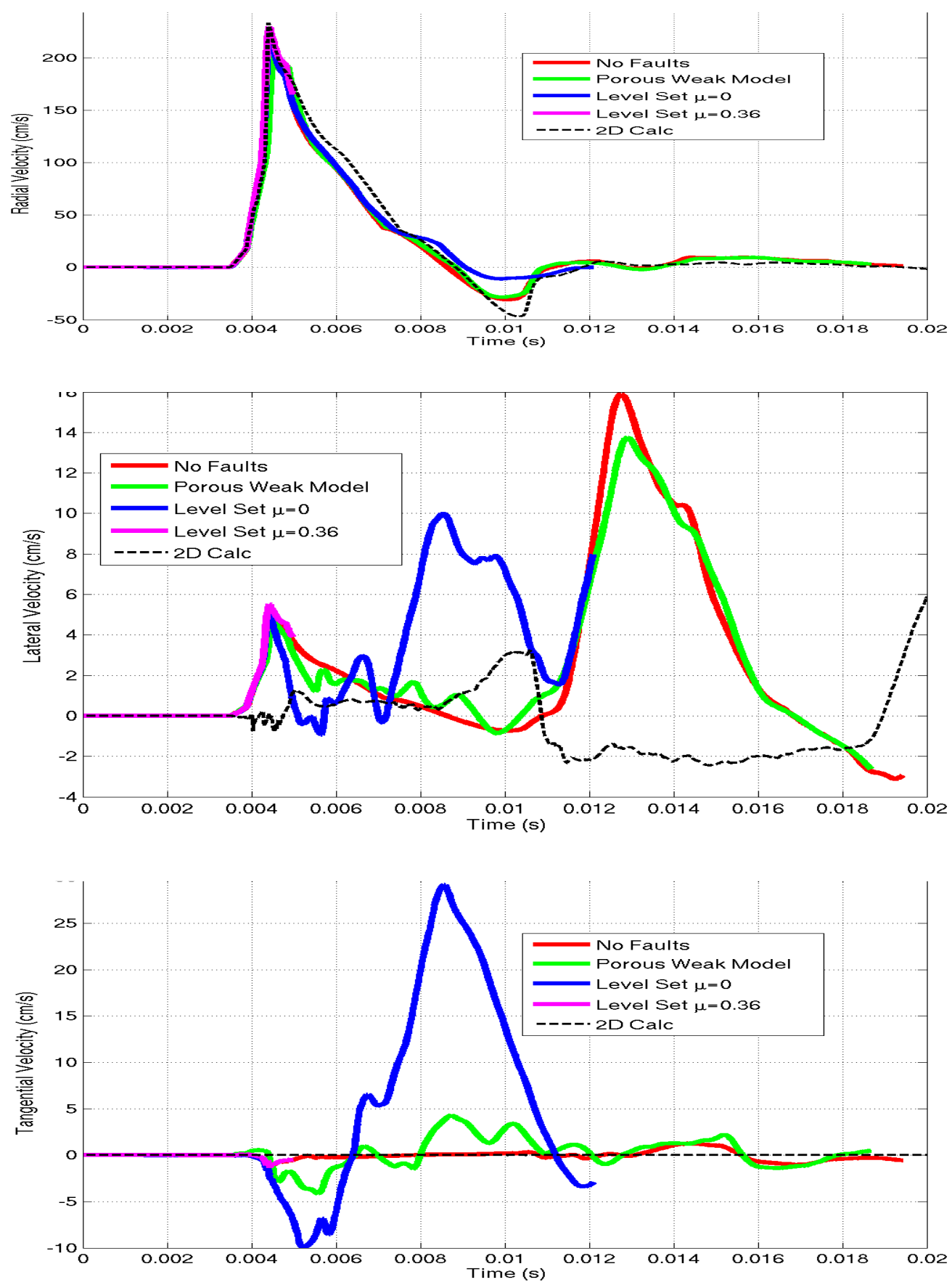

Figure 28 Predicted velocity histories in borehole U15n\#6 at a depth of $150 \mathrm{ft}$. 

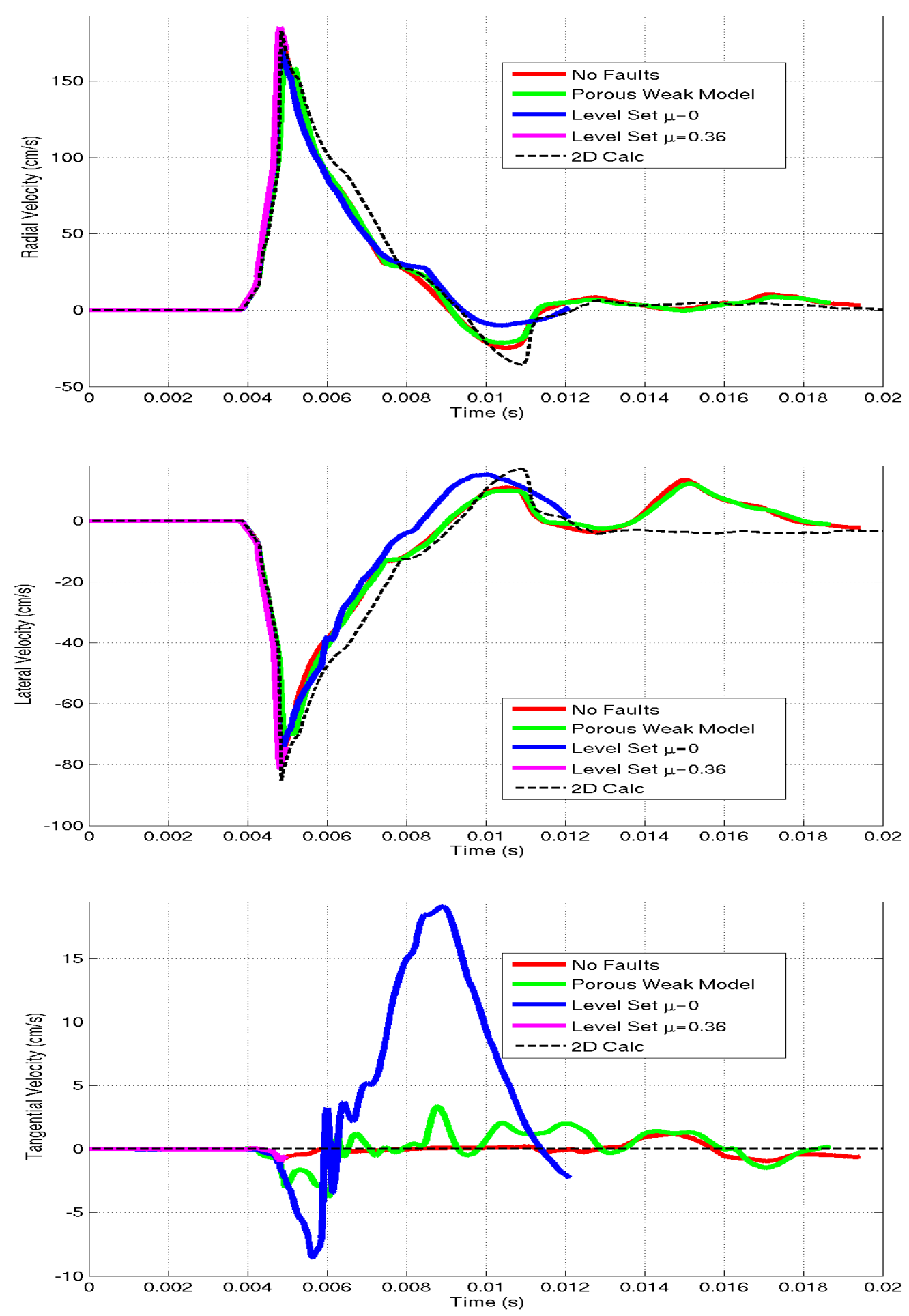

Figure 29 Predicted velocity histories in borehole U15n\#6 at a depth of $180 \mathrm{ft}$. 
The simulation results at all the borehole stations are shown in Figures 12-29. In each figure the radial, lateral and tangential velocities are plotted from top to bottom. The 5 solutions at each station are denoted by red, green, blue, pink and black curves, respectively. The results show generally that the two faults, represented by weak materials, have no significant effect on the wavefields in comparison with those without any faults (in 2D and 3D). But it is clear that in the case of a pure slip surface (solution 3, blue), implemented with the level set method, significant wave modulations occur at stations \#2 (Figure 16) and \#3 (Figure 19). There is a peak velocity reduction close to $20 \%$, although the pulse widths are little affected. Station \#1 (Figures 12-14), is at the same distance as station \#2 but the shock waves penetrate fault \#1 almost normally to reach this station so that the effect should be lessened. However with a friction angle of 20 degrees (commonly used in geological materials and less than what was observed in the shear experiment), the effect of the faults at the inner ring stations (stations 1-3) seems to disappear, i.e. the shock waves are not strong enough to cause the two sides the faults to dislocate relative to each other even at the close-in distances.

At the outer ring stations \#4-6 the effects of the two faults are all nominal (Figures 21-29) and the solutions almost come close to each other, indicating the effects of the faults dissipate with distance quite rapidly. This is also seen in figures 30-33, showing waveforms at 10,15 and $20 \mathrm{~m}$ and azimuths of 30, 90, 150 and 270 degrees (in the proximity of the azimuth of stations 1, 5, 3 and 2 , respectively). Results are compared for two friction angles, 0 ( $u=0$, dashed line) and 20 degrees ( $u=0.36$, solid line). The shock waves propagate to the west from the explosion and pass fault \#2. At azimuths of 150 degrees ( azimuth of station \#3) and 270 degrees ( azimuth of station \#2), the difference between the two solutions with the two friction coefficients is more evident at $10 \mathrm{~m}$ than at $20 \mathrm{~m}$, suggesting that the effect of the faults is limited to short distance. It is also seen the waves are dominated by the radial components and the tangential components are quite negligible at these borehole stations. 

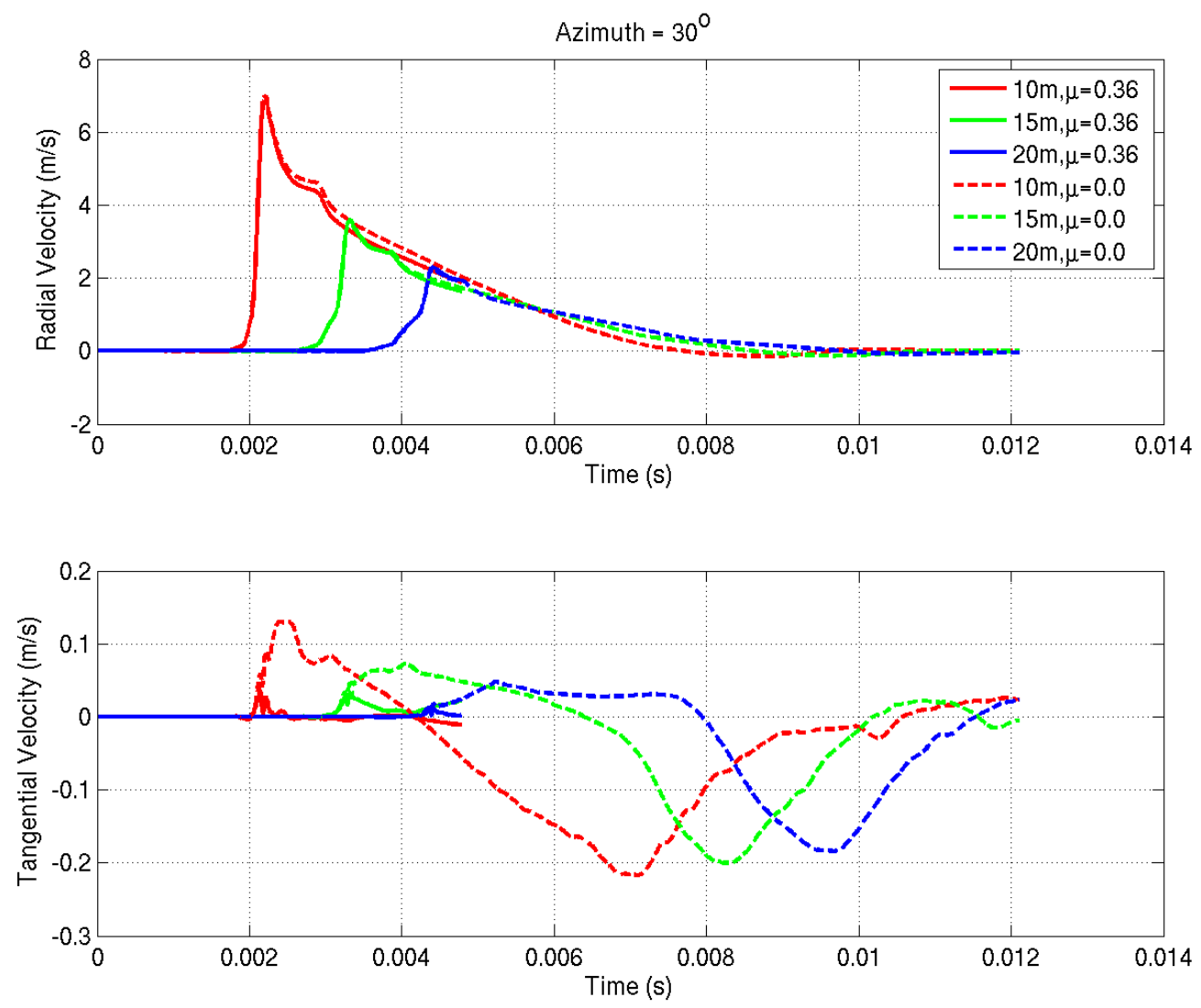

Figure 30 Wave evolutions from $10 \mathrm{~m}$ to $20 \mathrm{~m}$ at shot depth and azimuth of 30 degrees (close to that of station \#1 in Figure 1). Solid and dashed lines represent friction coefficients of $\mu=0.36$ and $\mu=0$, respectively. The top denotes the radial component and the bottom the tangential component. The effect of friction coefficient is small on the radial component at this azimuth since the wave nearly propagates normally through fault \#1. The tangential components are evidently insignificant. 

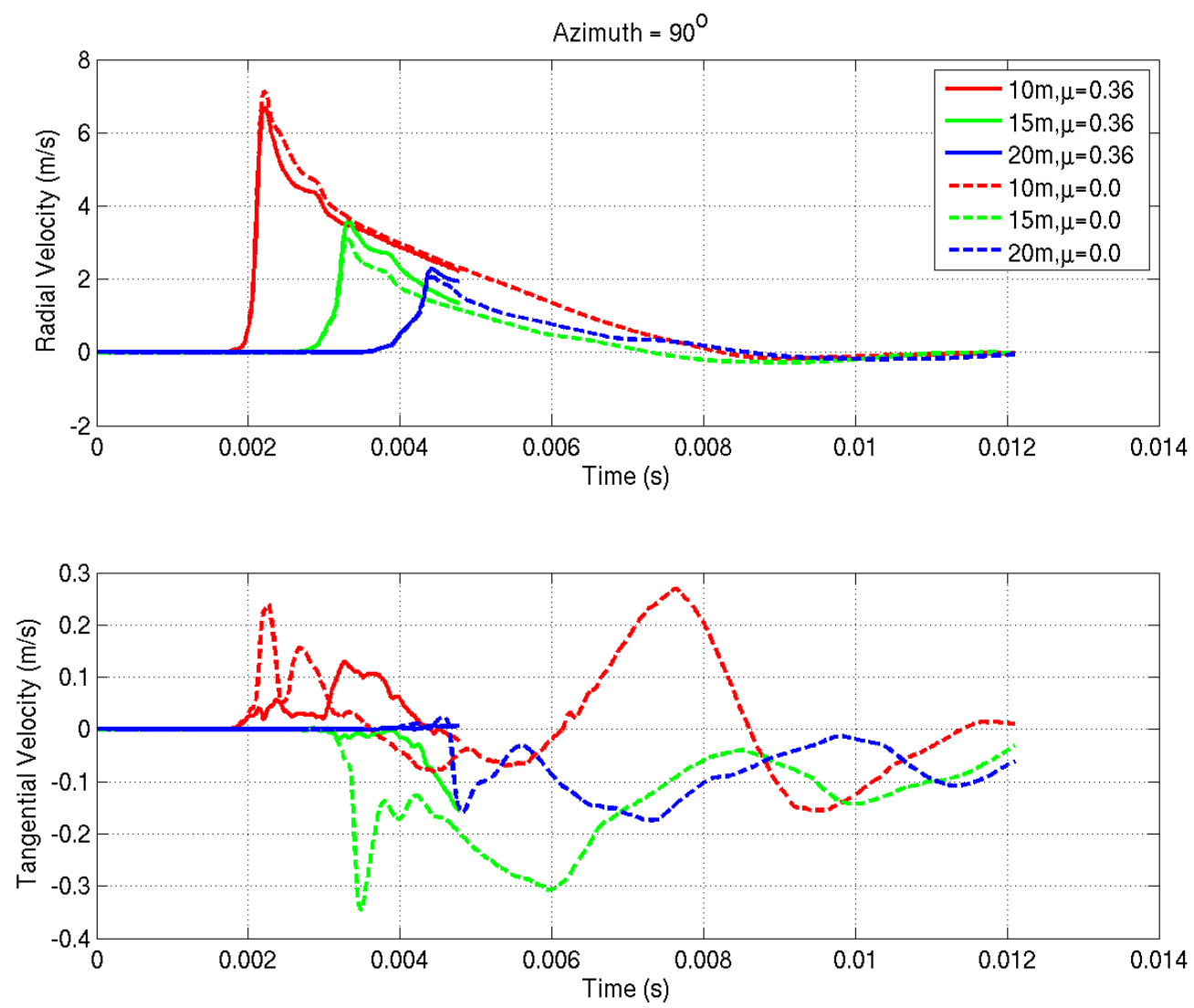

Figure 31 Similar to Figure $\mathbf{3 0}$ but at an azimuth of $\mathbf{9 0}$ degrees (close to that of station \#5). The effect of fault \#1at this azimuth is still small. 

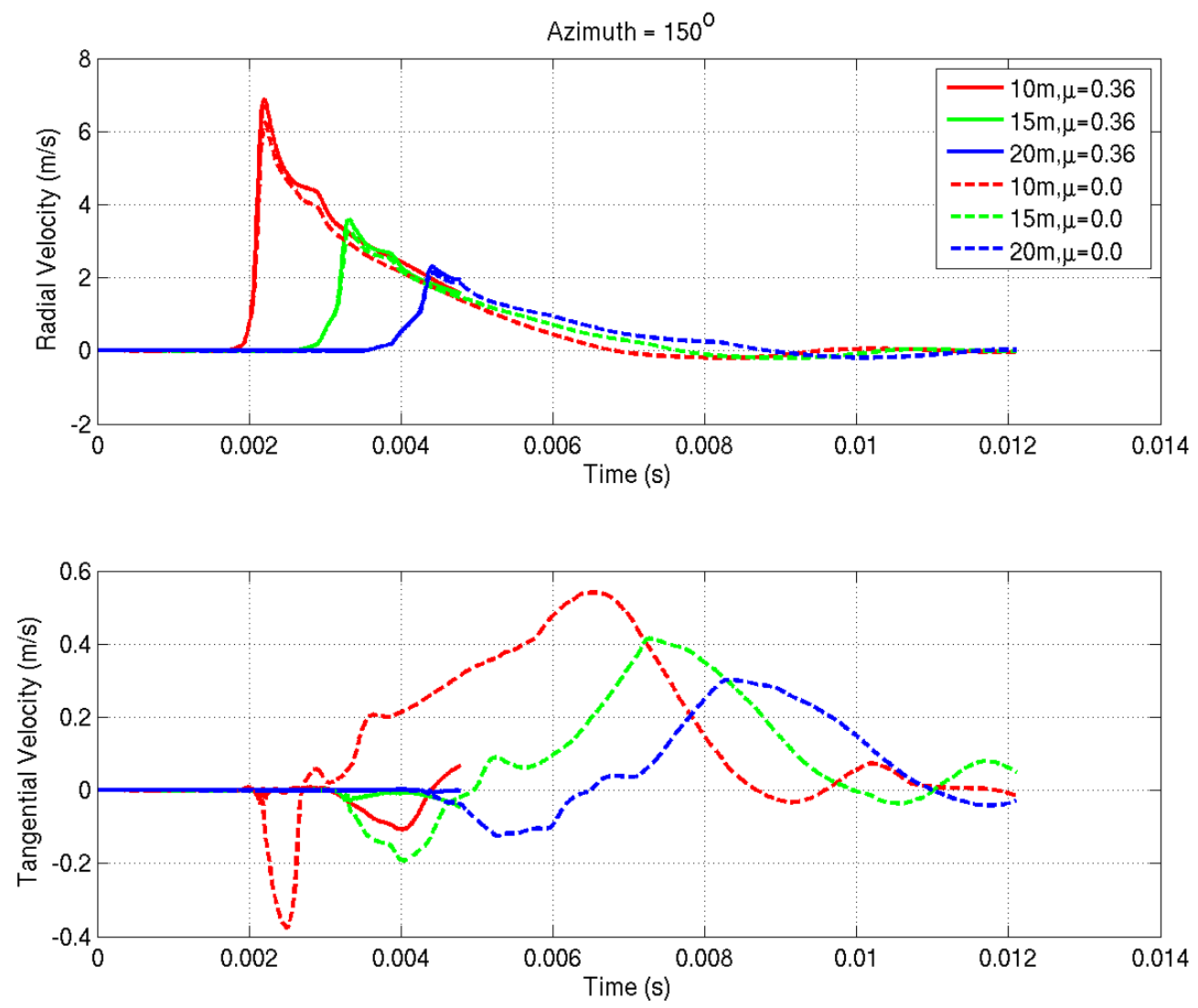

Figure 32 Similar to Figure $\mathbf{3 0}$ but at an azimuth of $\mathbf{1 5 0}$ degrees (close to that of station \#3). The effect of fault \#2 with no friction is seen to reduce the peak amplitudes at $10 \mathrm{~m}$ but the difference between friction coefficients of 0.36 and 0.0 diminishes up to $20 \mathrm{~m}$. 

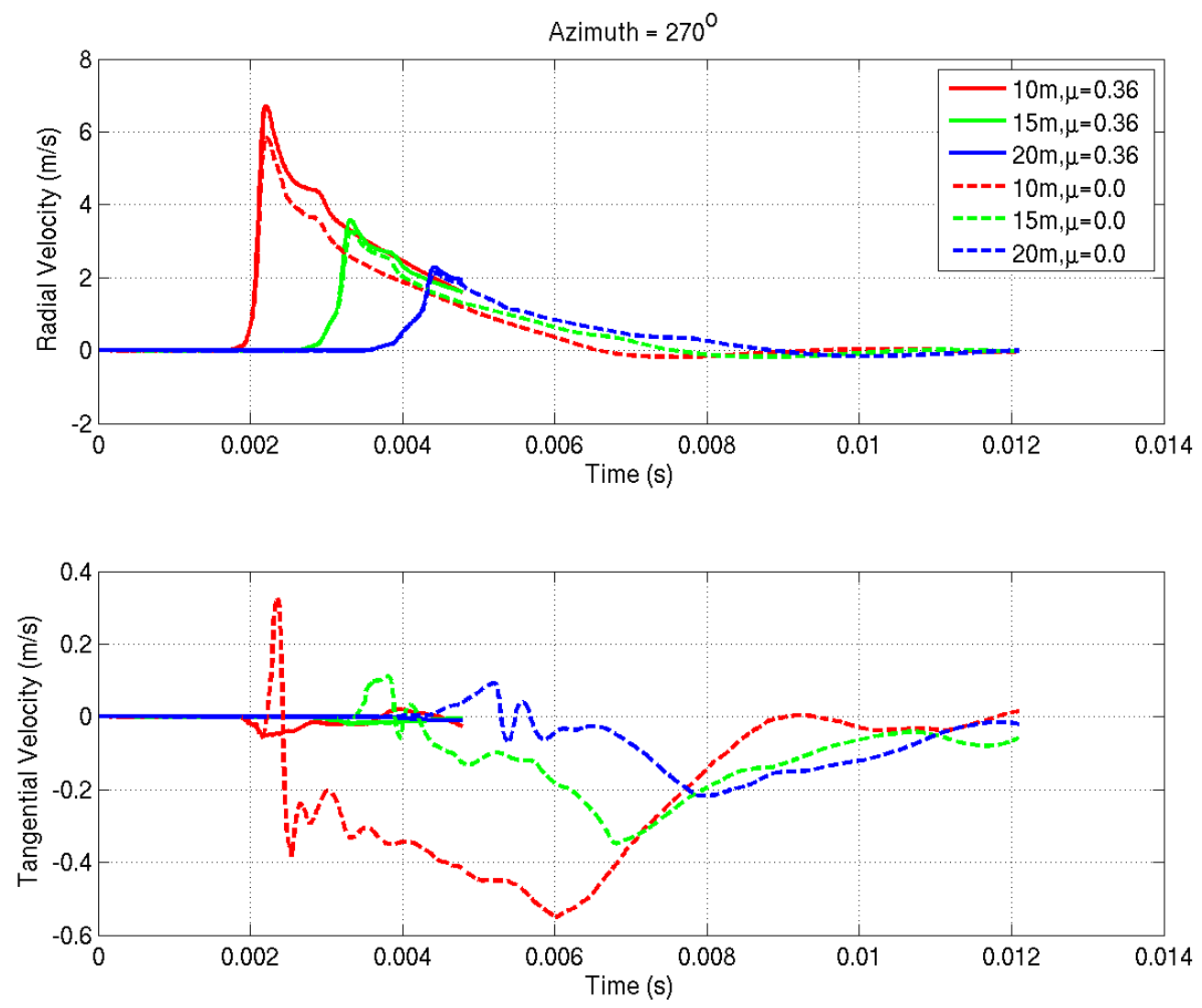

Figure 33 Similar to Figure $\mathbf{3 0}$ but at an azimuth of $\mathbf{2 7 0}$ degrees (close to that of station \#2). The effect of friction on fault \#2 surface is seen clearly on the peak amplitude reduction. Again the difference decays with distance. The pulse widths are not affected by friction on the fault plane.

\section{COMPARISON OF WAVEFIELDS ACROSS THE FAULT PLANE}

The effect of the two faults is further illustrated by the solutions at the two adjacent locations across the fault plane. Figure 34 shows the 4 pairs of stations across the fault plane at the SPE 2 shot depth and comparisons of the wavefields are shown in Figure 35-38 At the A and B paired 
locations the fault effects are pronounced in the amplitude reduction, compared with the other two $C$ and $D$ paired locations; this might be attributable to the larger incident angles on the fault plane at $A$ and $B$ than at $C$ and $D$ locations.

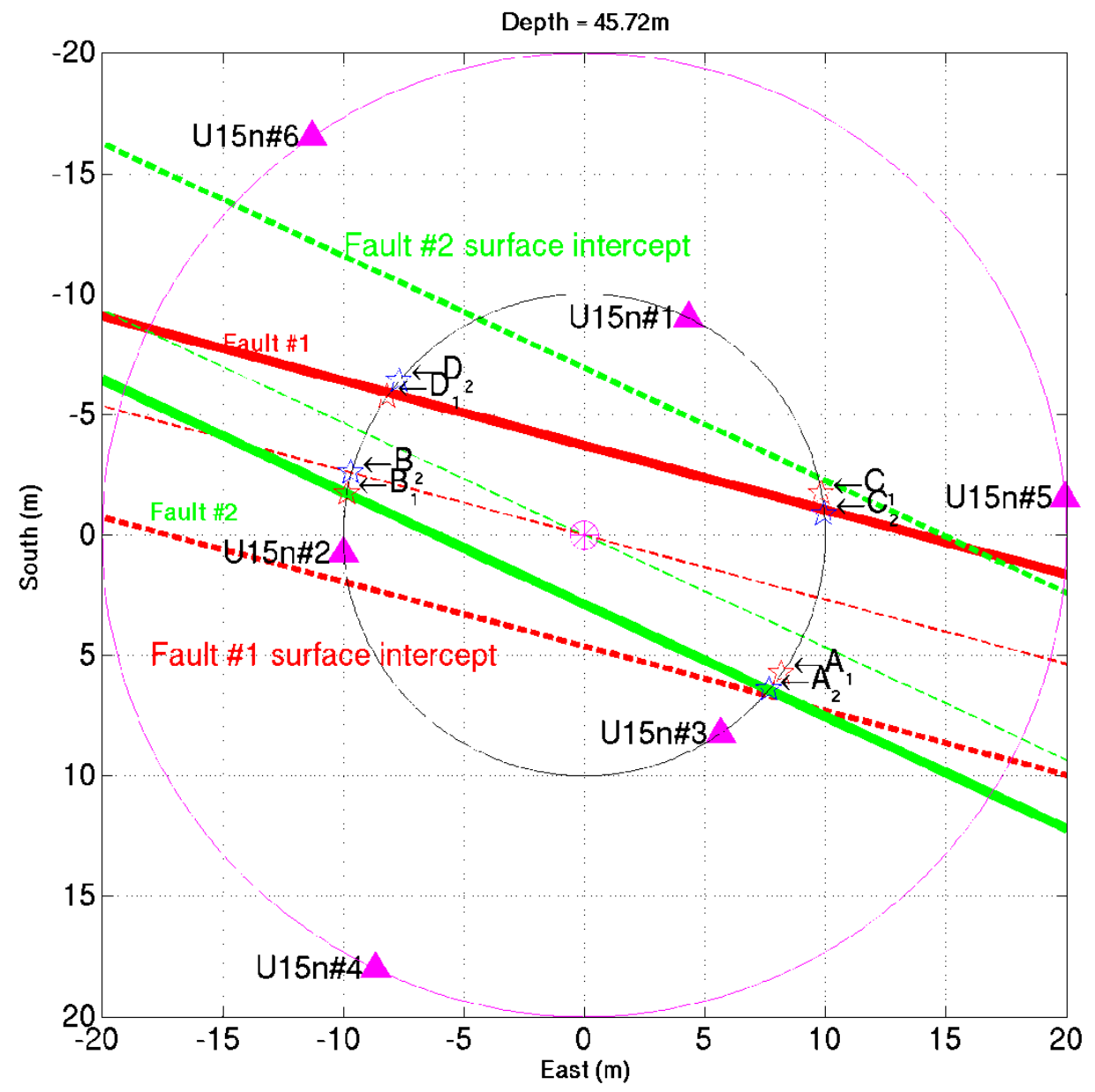

Figure 34 Location pairs across the two faults. 

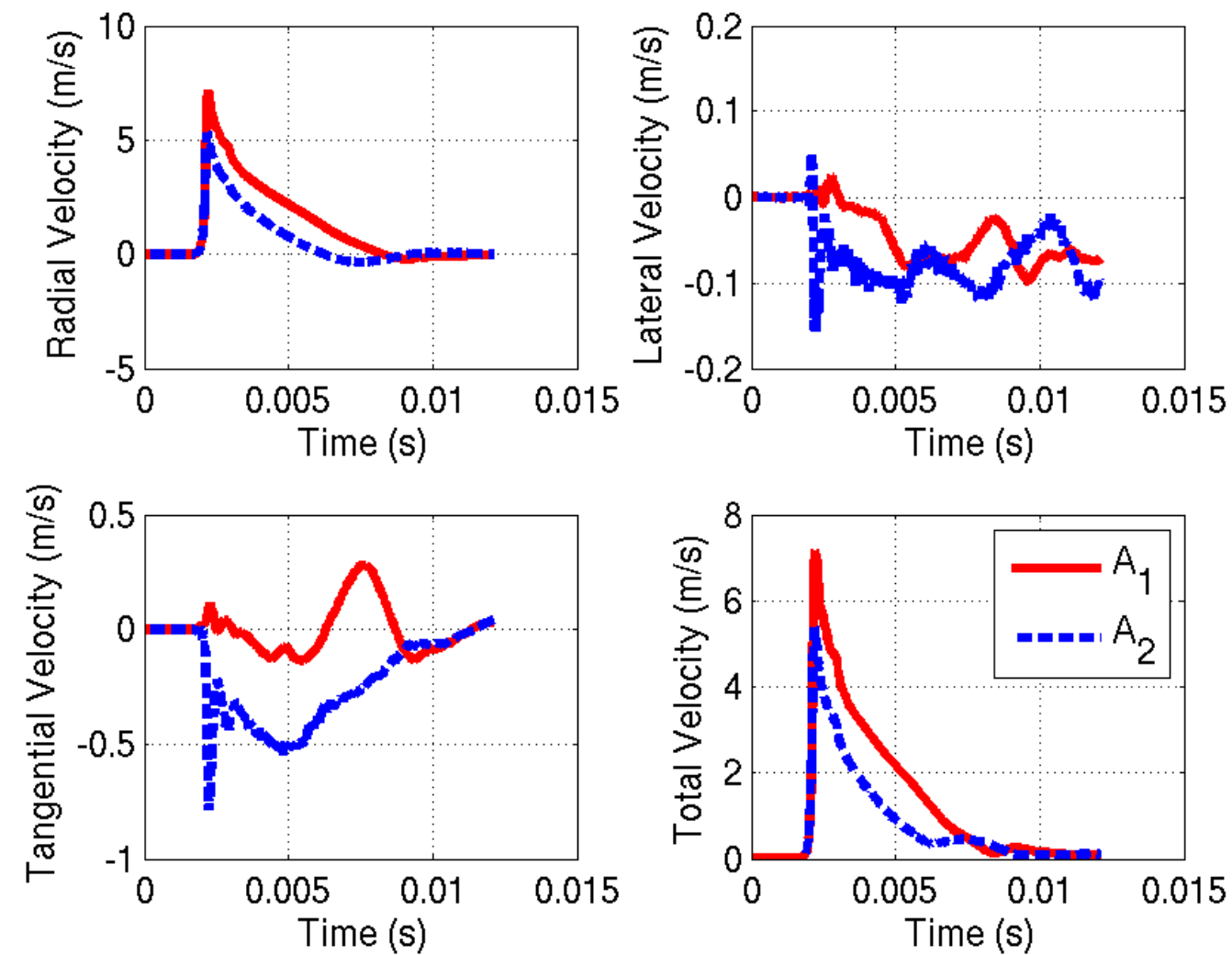

Figure 35 Waveform comparison between the two locations A1 and A2 across fault \#1 

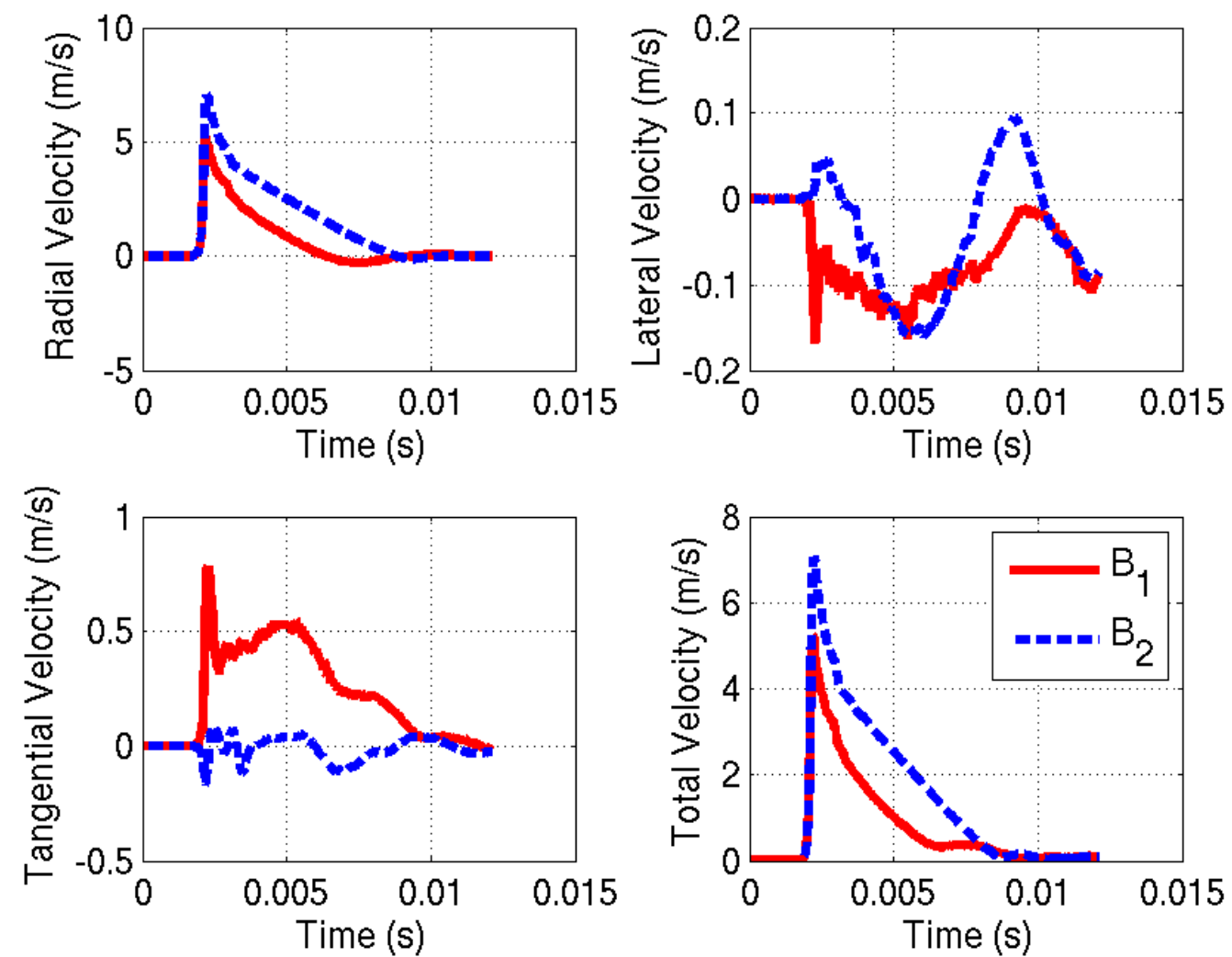

Figure 36 Waveform comparison between the two locations B1 and B2 across fault \#1 

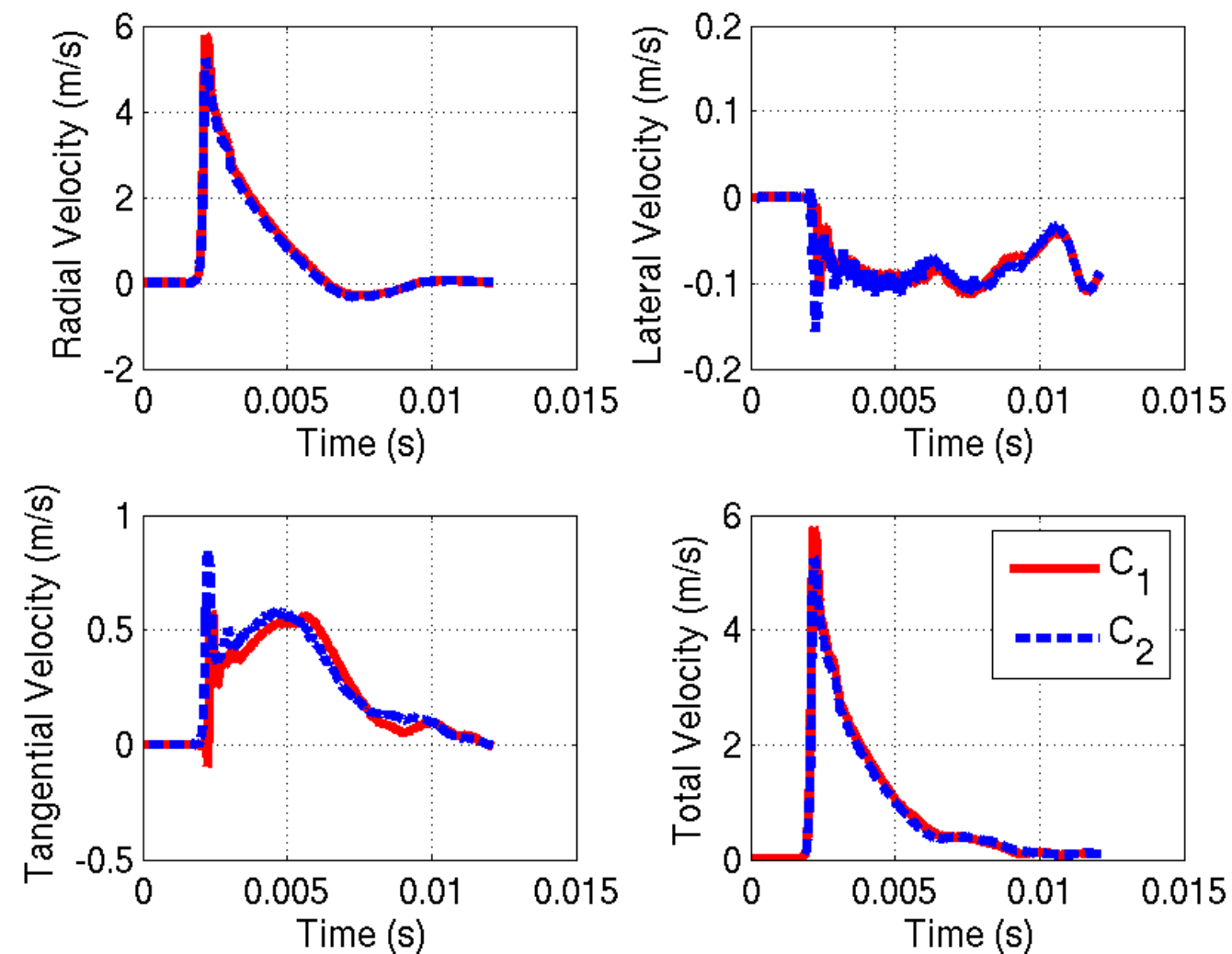

Figure 37 Waveform comparison between the two locations C1 and C2 across fault \#2 

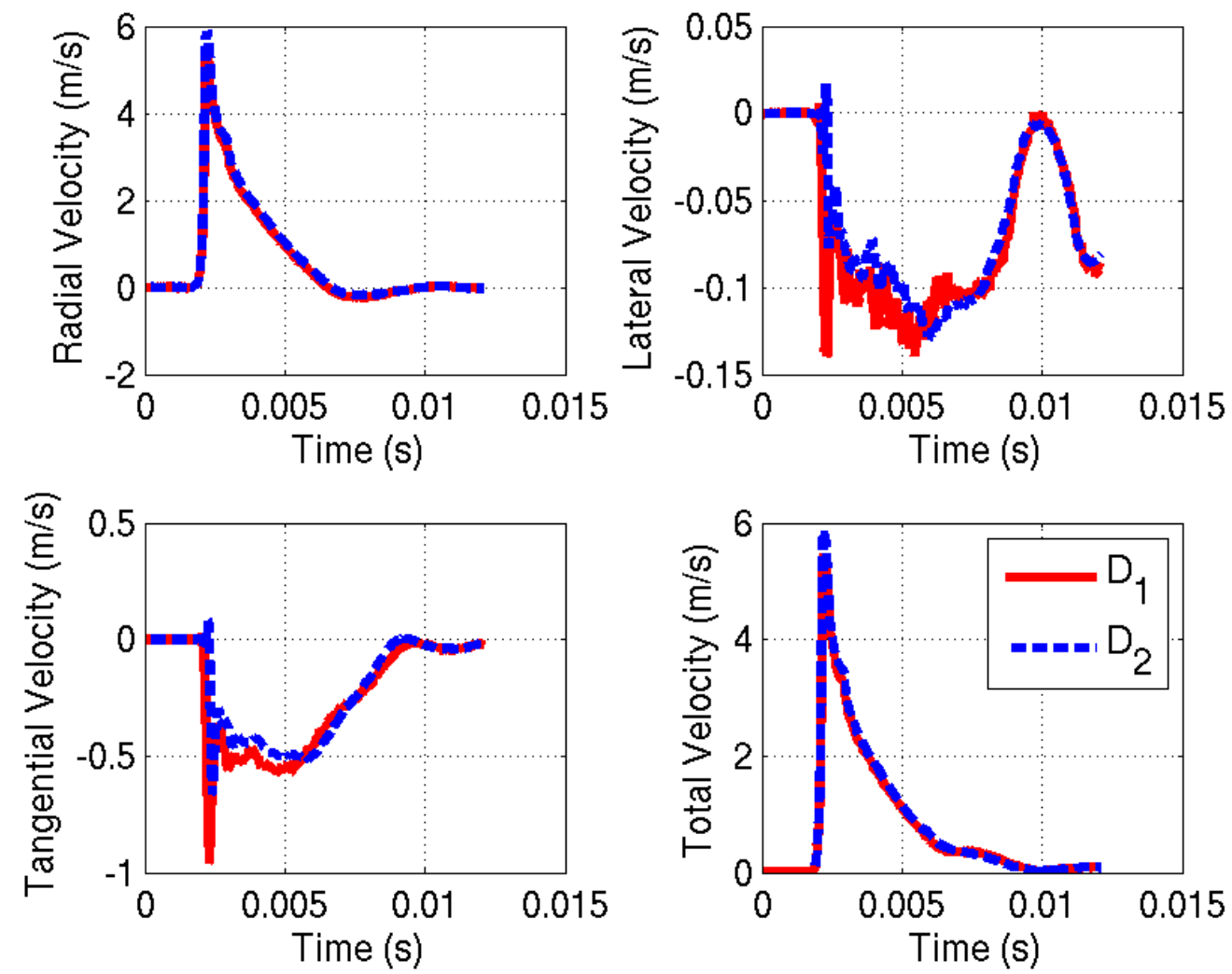

Figure 38 Waveform comparison between the two locations D1 and D2 across fault \#1

A pressure snapshot at the shot depth at $1 \mathrm{~ms}$ for the case of no friction on the fault surface is shown in Figure 39. The two fault traces are also plotted. The contours show a little asymmetry with slight reflections visible near the two faults. Note the $x$-axis is positive east, $y$-axis is positive up, and z-axis is positive south. The fault traces are found not to be visibly bulged by this 2200lb explosion since the maximum possible displacement on the fault surface must be less than $10 \mathrm{~mm}$ based on the estimated displacement at station \#2 (e.g., Figure 16) but the minimum spacing in the calculation is $60 \mathrm{~mm}$ which is much greater than the displacement. 

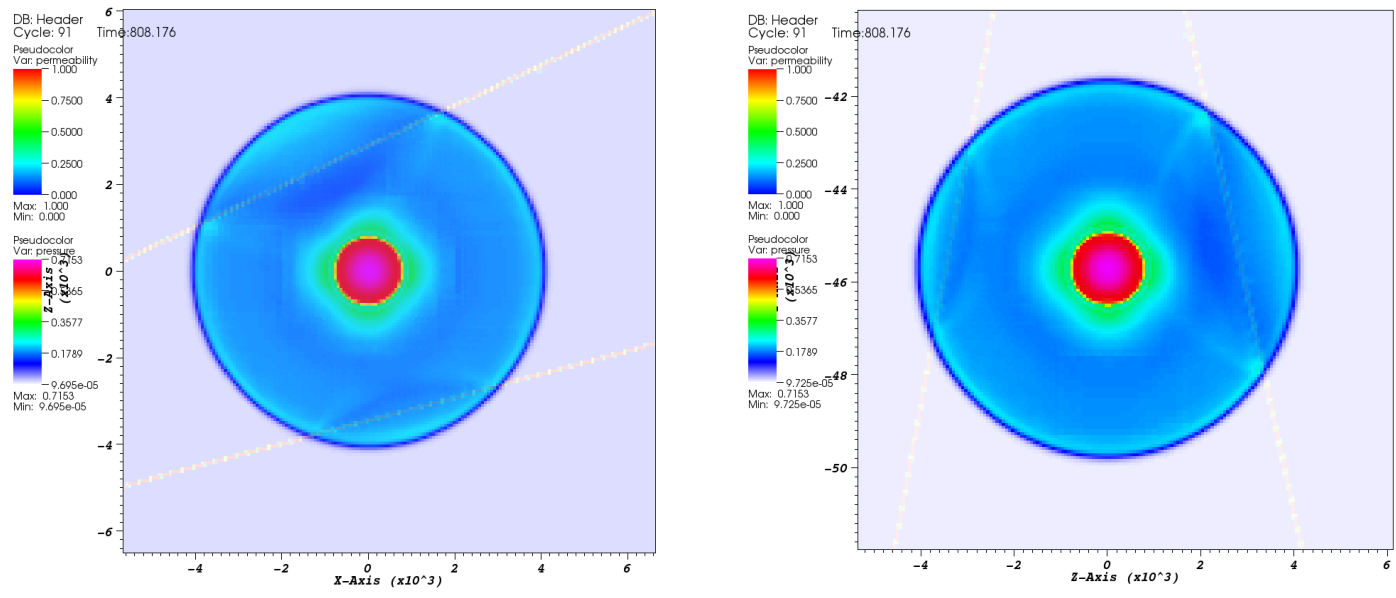

Figure 39 Pressure snapshot at $0.8 \mathrm{~ms}$ at the horizontal shot depth slice (left) and vertical slice (right). The faults are represented as pure slip surfaces for the extreme cases. The $\mathrm{X}, \mathrm{Y}$ and $\mathrm{Z}$ axes correspond to east, up and south directions, respectively. The contours show some asymmetry and reflections near the faults (white traces). The fault traces seem not to move visibly from their initial positions due to the nominal displacement.

Velocity snapshots are shown in Figure 40. Again slight reflections are apparent near the faults and the wavefield asymmetry is insignificant for the $2570 \mathrm{lb}$ explosion. Figure 41 shows the extent of nonlinear deformation in the two slices and it is seen that the nonlinear region seems to be limited around $20 \mathrm{~m}$. There is seen to be clear asymmetry in the plastic work done on the hard rock, which could be attributed to the slip condition on the fault surface by means of modulating the shearing components.
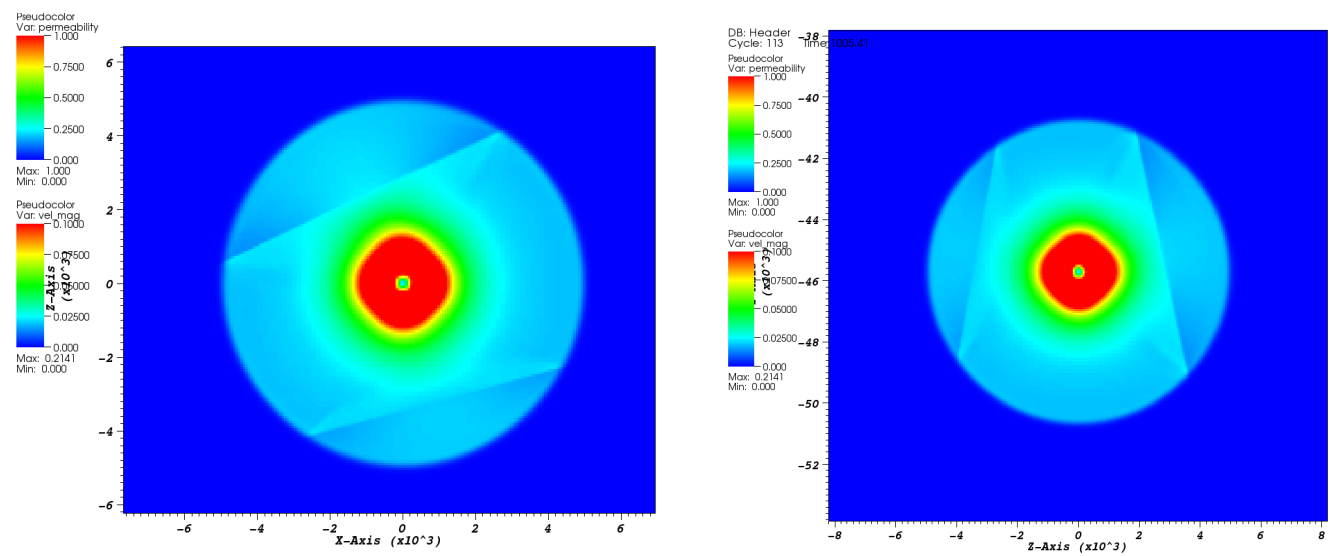

Figure 40 Velocity magnitude contours at the horizontal shot depth slice (left) and vertical slice (right). Again the reflections are apparent near the faults. 

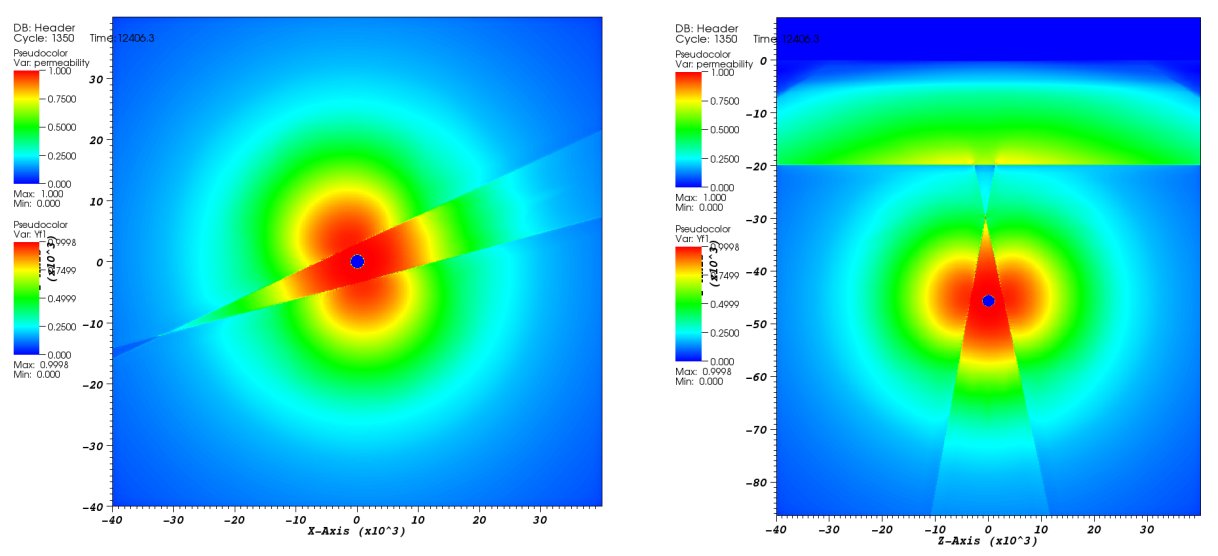

Figure 41 Plastic deformation extent at the horizontal shot depth slice (left) and vertical slice (right). The nonlinear deformation is seen to extend to about $20 \mathrm{~m}$ around the source. The top weathered layer (right plot) is represented as weak porous granite and so it is also yielded. 


\section{Three Dimensional Discrete Simulations of the SPE2 shot}

SPE2 predictions with GEODYN-L were performed using the same joint and fault geometry as the ones used for the SPE1. The source size was increased to yield the required amount of energy, equivalent to $2572 \mathrm{lb}$ of ANFO. The source was assumed to be spherical.

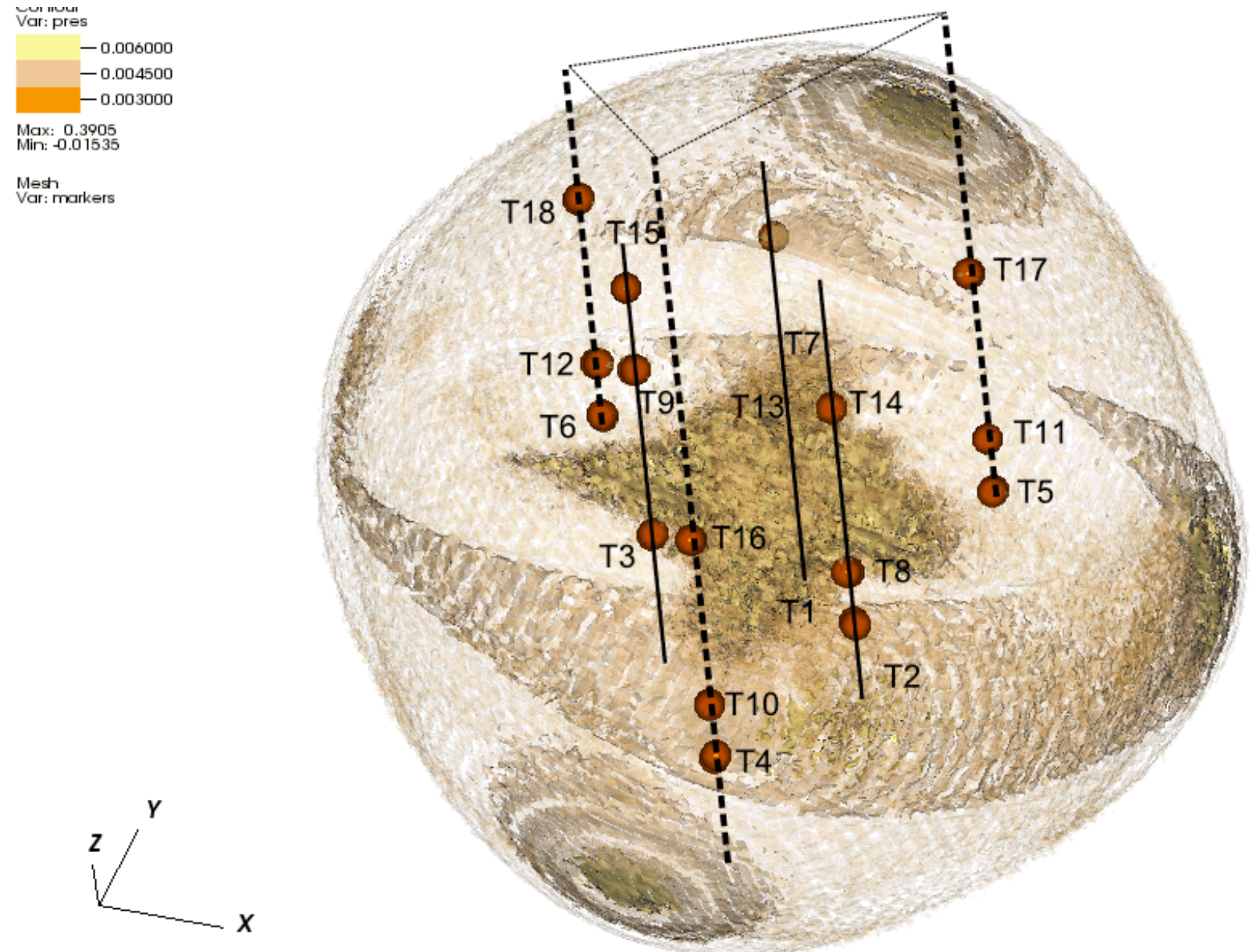

Figure 42 3D pressure contours at $9 \mathrm{~ms}$ and target point location for SPE2 simulation.

Figure 42 shows the locations of the target points in the discrete calculations as well as the wave shape at $9 \mathrm{~ms}$. Note, that the numbering of the target points is not identical to one used in the experiment (for example, T2 correspond to \#3 and T3 correspond to \#2). The pressure wave has distinct anisotropy cased by the joints. Horizontal radial velocities (which will be measured in 
the experiments) show variability up to a factor of two in peak velocity and a factor of 3-4 in peak displacement as shown in Figure 43. Predicted peak radial velocities are roughly 3 times higher than calculated at the same stations for SPE1. Figure 44 and Figure 45 show comparison of the velocity histories calculated in 2D continuum GEODYN-L simulations using the ensemble model for granite and the same source versus the 3D discrete simulations. At $10 \mathrm{~m}$, the continuum model yields a wider displacement and roughly the same peak velocity but, at $20 \mathrm{~m}$, it lower velocity and about the same pulse width. Discrete simulations show the effect of joins similar to those observed in SPE1 simulations. The highest horizontal velocities are observed in normal to joint locations (T7 and $\mathrm{T} 10$ at the source level). Peak radial velocities and displacements at different locations are shown in Figure 46 and Figure 47.

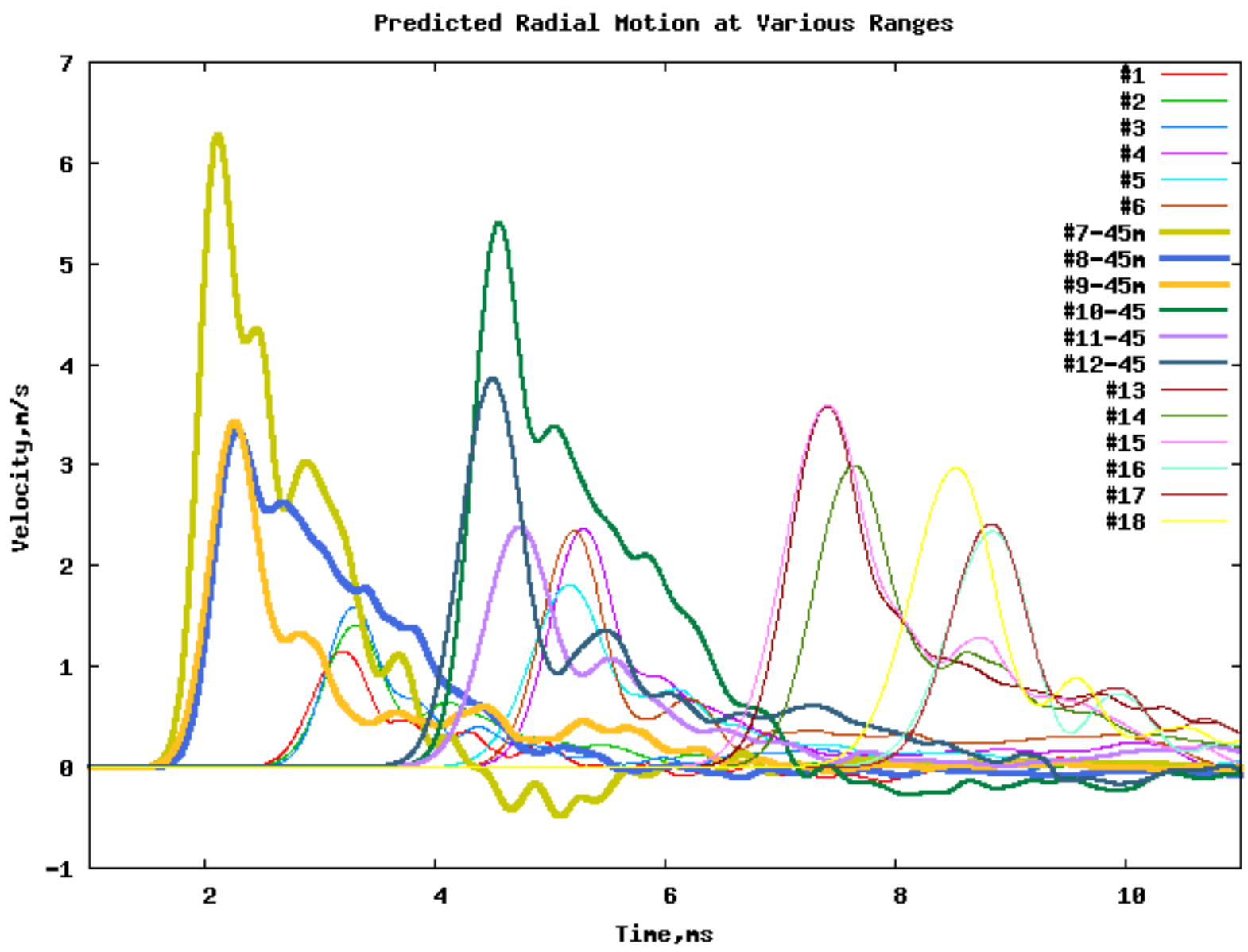

Figure 43 Horizontal (radial) velocity evolution calculated for SPE2 event at various gauge locations. 

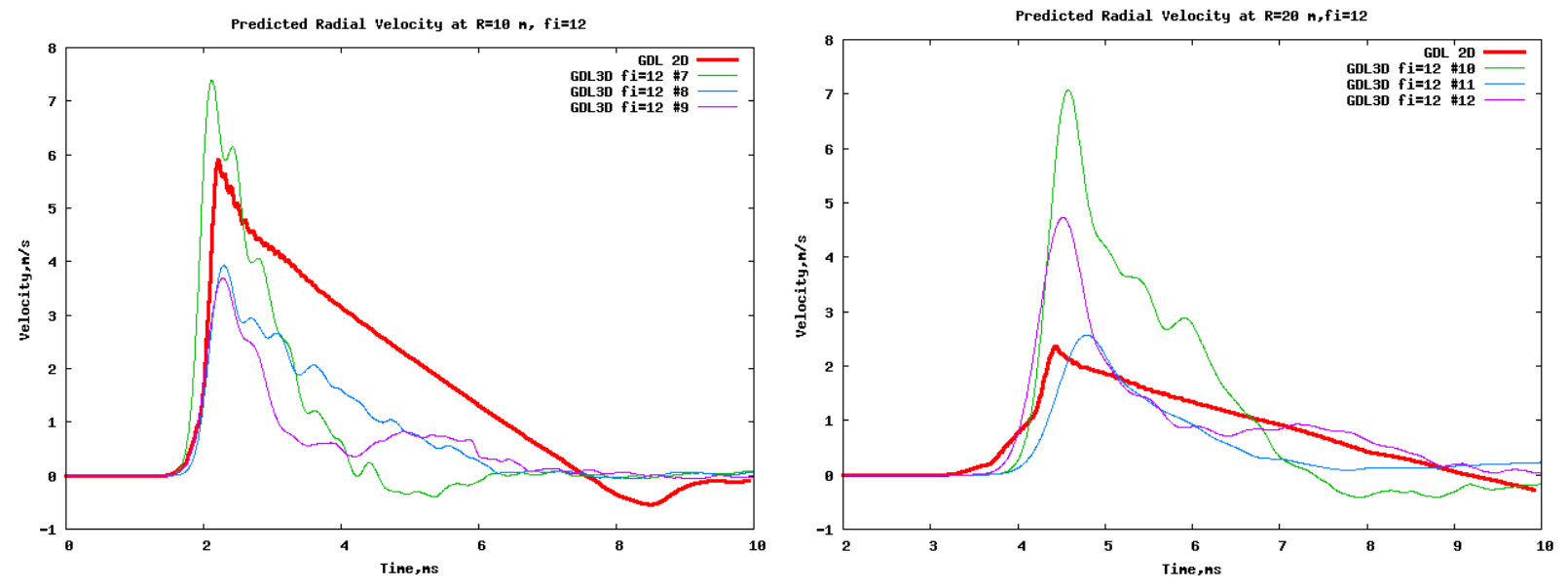

Figure 44 Comparison of discrete simulations with the intact model and joint friction of 12 degrees vs contin uum simulations using the "ensemble" model for granite.
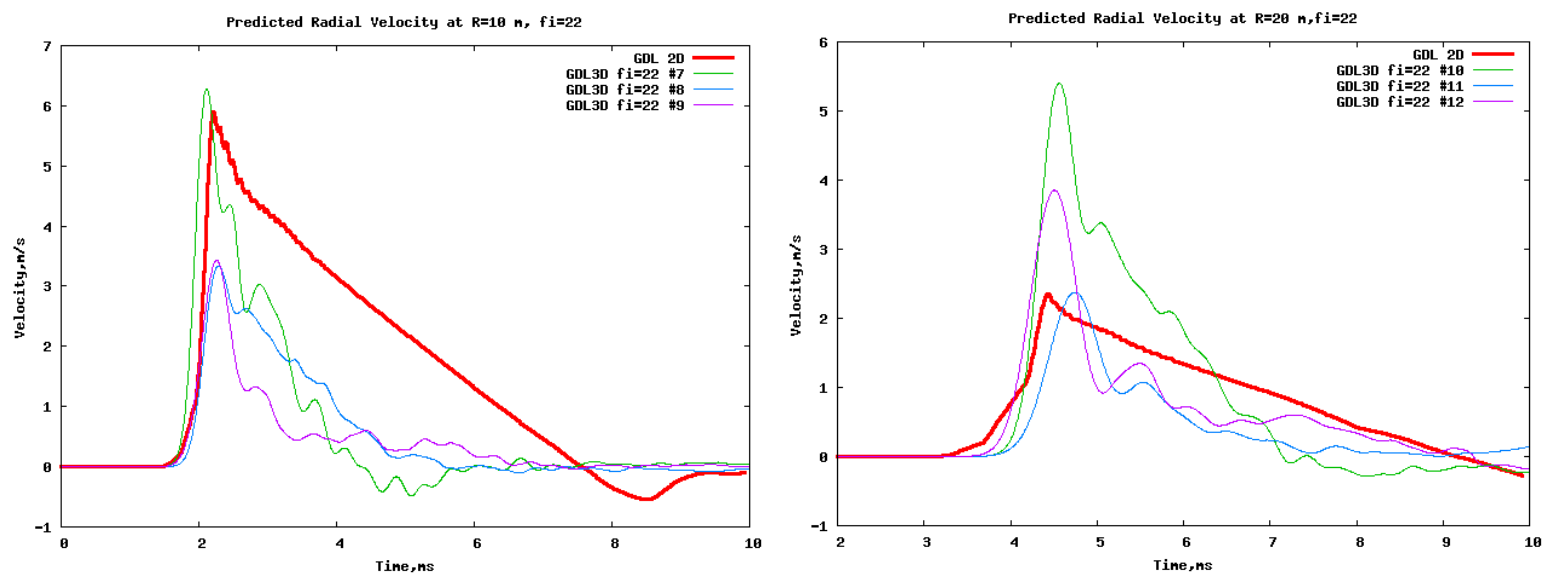

Figure 45 Comparison of discrete simulations with the intact model and joint friction of 22 degrees vs continuum simulations using the "ensemble" model for granite. 


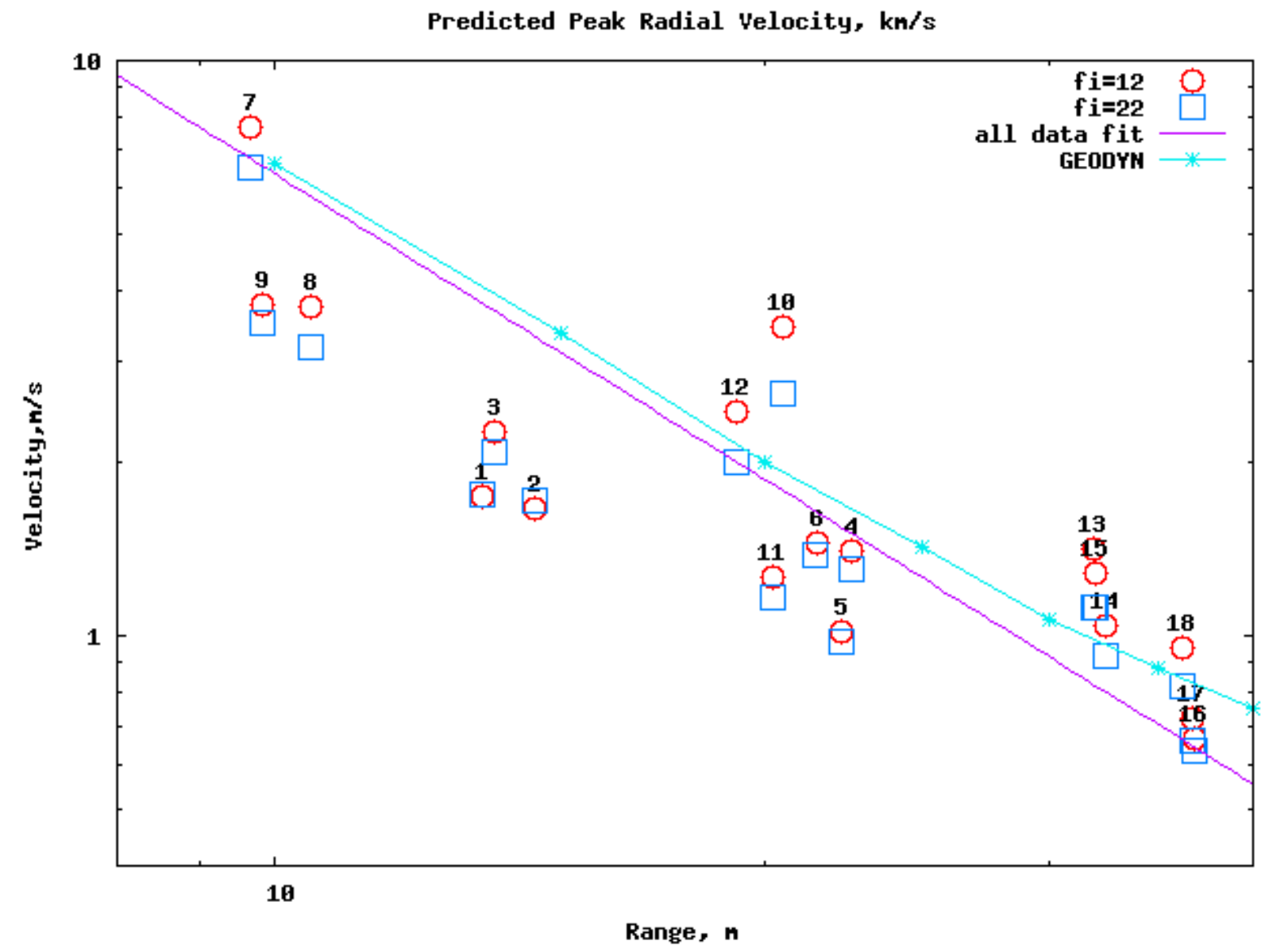

Figure 46 Peak radial velocity attenuation calculated at various stations using the discrete model with two different friction angles for joints. The nuclear data fit is shown with a straight line, GEODYN continuum calculation is shown with the line with markers.

Similar to the SPE1 prediction, GEODYN calculations show peak velocities and displacements above the nuclear data fit line. 


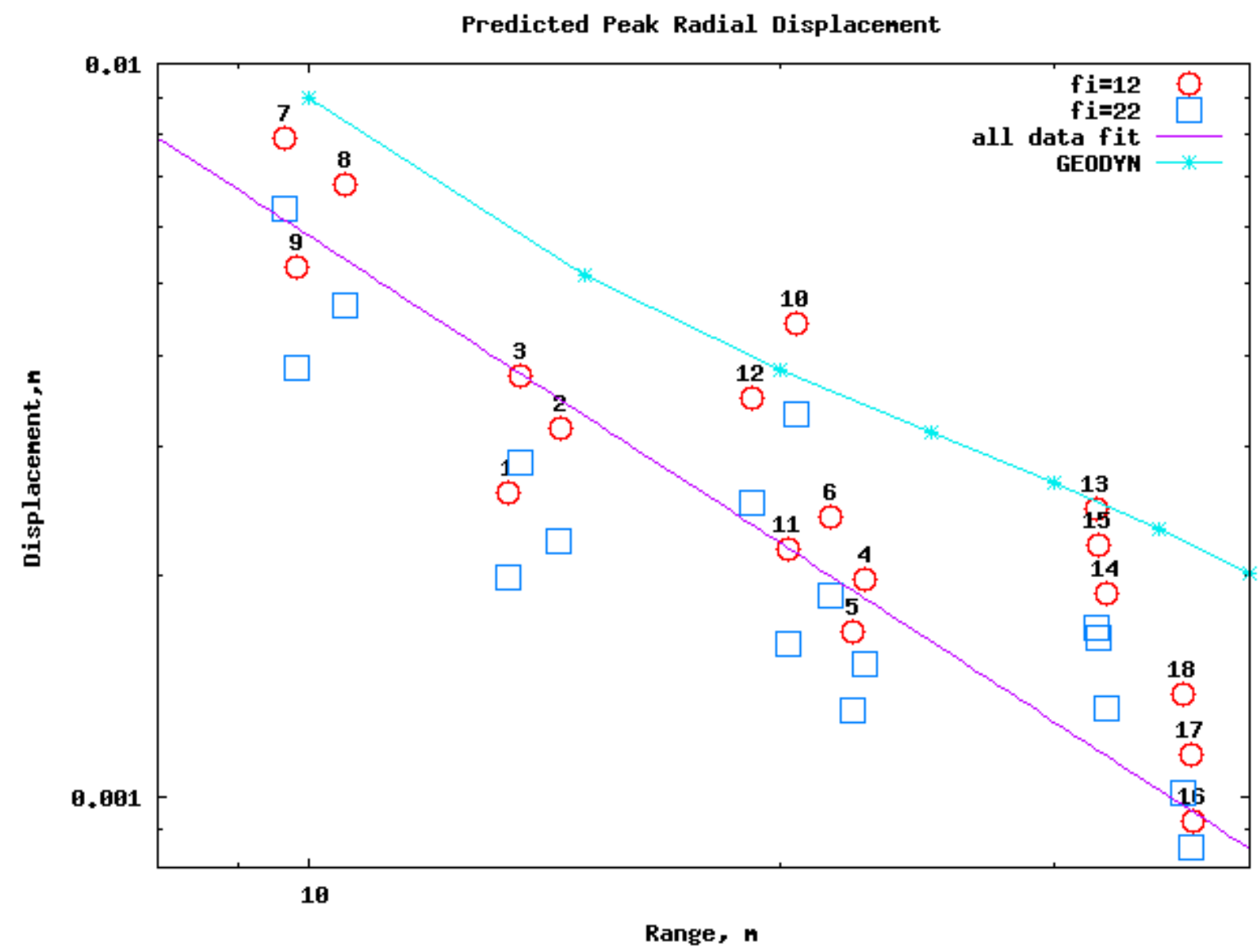

Figure 47 Peak radial displacement attenuation calculated at various stations using the discrete model with two different friction angles for joints. The nuclear data fit is shown with a straight line. The top line with markers corresponds to GEODYN calculations with the ensemble model.

The effect of faults was evaluated by painting a $0.5 \mathrm{~m}$ thick layer of weak material across the blocks. Figure 48 shows effect of the faults on the velocity evolution for the stations located at the depth of the source $(45 \mathrm{~m})$. The biggest effect is observed for T9 and T12 and a very small effect is observed for T7 and T10 which are almost normal to the faults. 

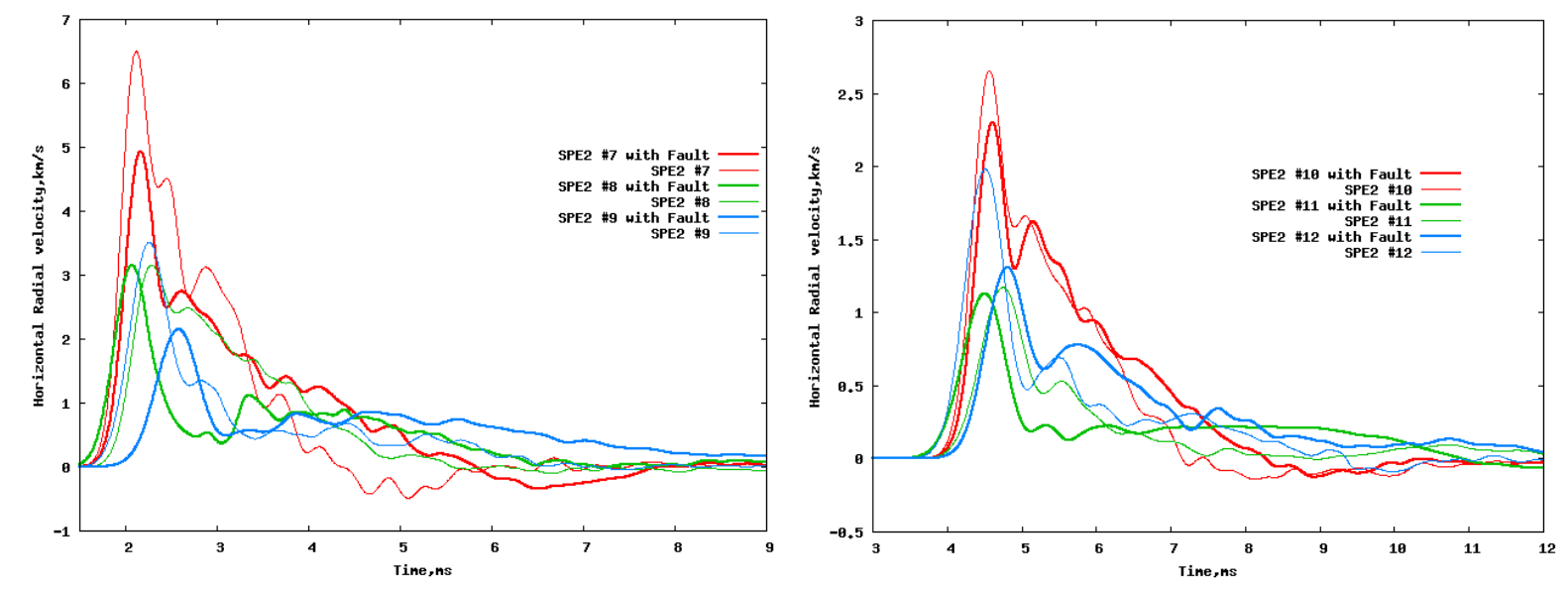

Figure 48 Effect of fault on calculated velocities for the stations at the depth $45 \mathrm{~m}$.

\section{CONCLUSIONS}

- We have used the nonlinear codes GEODYN and GEODYN-L to predict near field motions associated with the first two SPE shots, SPE 1 and SPE 2. Both 2D axisymmetric and fully three dimensional simulations were performed. The two main faults in the testbed were simulated using two significantly different methods and the results show that these faults have a relatively small effect on the simulated wave motion response.

- The numerical simulations with GEODYN show that the motions generated by SPE 2 are still dominated by spherical waves and the faults have only nominal effect on the wavefields at the outer ring stations. The peak amplitudes are evidently reduced in the case without fault surface friction as an extreme scenario at inner ring stations, especially at stations $\# 2$ and \#3, which are located just behind the fault. With realistic surface friction angles observed in the shear experiments, the effects due to the two faults become insignificant even at the inner ring stations.

- Using discrete simulations, we have demonstrated that azimthuthal variation of peak velocity and displacement is likely caused by the presence of joints in the rock mass. If joint density and orientation are well known this information can be used in the computational analysis to explain the observed anisotropy of wave propagation.

- In the discrete simulations we relied on 1) intact data provided for the core sample, 2) granite joint properties available from the literature, 3) assumptions that the joints are wet and their effective friction is smaller than measured under quasi-static conditions (which also follows from our separate meso-scale study on dynamic loading of wet 
joints, not included in this report). The intact model used for granite blocks has not been calibrated for shock wave conditions (unlike the ensemble model used to describe large scale events). There is a possibility that this model needs to be tuned to better match granite properties especially under dynamic conditions. For example, no softening features were used for the blocks to describe strength degradation due to distortional damage or thermal softening. Also, the model may overestimate the strength at high confinement. The goal of the discrete study was to show that the joints may play a significant role in defining the effective strength properties of a rock mass.

- We have shown, that there is no need to scale the mechanical model determined from laboratory measurements on intact rock samples if the joints in the rock are accounted for. The calculations shown are the first of this kind and they require massively parallel computer clusters which are not yet widely available.

This work performed under the auspices of the U.S. Department of Energy by Lawrence Livermore National Laboratory under Contract DE---AC52---07NA27344.

\section{REFERENCE}

1. Antoun, T.H., Lomov, I.N., and Glenn, L.A. "Development and Application of a Strength and Damage Model for Rock under Dynamic Loading," Proceedings of the 38th U.S. Rock Mechanics Symposium, Rock Mechanics in the National Interest, Edited by D. Elsworth, J. Tinucci, and K. Heasley, A.A. Balkema Publishers, Lisse, The Netherlands, 369-374 (2001)

2. Burchard, P., L-T Cheng, B. Merriman and S. Osher, "Motion of curves in three spatial dimensions using a level set approach", J. Computational Physics, 170, 720-741,2001

3. NSTEc UGTA/Boreholes Geology Group, "Projected Extent of Two Faults Encountered in Core Hole U-15n", March 08, 2011

4. Rubin, M.B, Vorobiev, O.Yu., Glenn, L.A., 2000, "Mechanical and numerical modeling of a porous elastic-viscoplastic material with tensile failure," Int. J. Solids and Structure, Vol.37, pp.1841-1871.

5. Schock, R. N., Heard, H. C., and Stephens, D. R., 1973, "Stress-Strain Behavior of a Granodiorite and Two Craywackes on Compression to 20 Kilobars," J. Geophys. Res., Vol.78(36), pp. 5922-5941. 
6. Vorobiev O.Yu, "Simple common plane contact algorithm", Int.Journ For Num.Meth in Engng. 2011 in press.

7. Vorobiev O.Yu and Antoun T., "Equivalent continuum modeling for nonlinear wave propagation in jointed media”, Int.J.Numer.Meth.Engng, 2011,pp. 1101-1124

8. Vorobiev O.Yu "Generic strength model for dry jointed rock masses", Int.Journ.of Plasticity 24,2008,pp.2221-2247

9. Lomov I.N., Antoun T. and Vorobiev O.Yu "Comparison of Joint Modeling Approaches Including Eulerian Sliding Interfaces”, LLNL-TR-421580, 2009 
